\title{
Mechanoluminescence of Nanoparticles
}

\author{
B.P. Chandra*
}

\author{
Disha Academy of Research and Education, Disha Institute of Management and Technology, Satya Vihar, Vidhansabha- \\ Chandrakhuri Marg, Raipur 492101 (C.G.), India
}

\begin{abstract}
Certain nanoparticles exhibit intense light emission during their elastic deformation, called the phenomenon of elastico mechanoluminescence (EML). When $\mathrm{ZnS}: \mathrm{Mn}$ and $\mathrm{SrAl}_{2} \mathrm{O}_{4}$ :Eu nanoparticles are deformed in the elastic region by the stress initially increasing with time and then attaining a fixed value or by the stress initially increasing and then decreasing with time or by the impact stress, then after a threshold pressure, initially the EML intensity increases with time, attains a maximum value and later on it decreases with time. For the fixed pressure or slowly decreasing pressure, the slow decay time of EML is equal to the lifetime of electrons in the shallow traps lying in the normal piezoelectric region of the crystals.In these cases, sometimes, fast decay of EML also appears and it is related to the machine -constant, that is, the decay time of strain- rate after the power to the cross-head of the machine is switched off. For the fast-deformation caused by impact stress, the fast decay time of EML is controlled by the rise time of impact stress, and the slow decay of EML gives the lifetime of retrapped electrons in the shallow traps. For $\mathrm{ZnS}: \mathrm{Mn}$ and $\mathrm{SrAl}_{2} \mathrm{O}_{4}: \mathrm{Eu}$ nanoparticles, the total EML intensity increases quadratically with the applied pressure. The diminished EML intensity of $\mathrm{SrAl}_{2} \mathrm{O}_{4}$ :Eu nanoparticles caused by number of pressings can be recovered by exposing the sample to UV-radiation. The tribo ML of $\mathrm{ZnS}: \mathrm{Mn}$ nanoparticles increases with increasing value of the load placed on the rotating rod inducing tribo ML. The EML spectra of $\mathrm{ZnS}: \mathrm{Mn}$ and $\mathrm{SrAl}_{2} \mathrm{O}_{4}$ :Eu nanoparticles are similar to their photoluminescence and electroluminescence spectra. The piezoelectrically-induced detrapping model is found to be suitable for the EML of nanoparticles and the expressions derived on the basis of this model are able to explain successfully the characteristics of the EML of nanoparticles. The EML of nanoparticles has been found useful in stress sensor and an EML-based safety-management monitoring system has been developed. The EML of nanoparticles can be used for the visualizations of stress distribution in solids, stress field near crack-tip, quasidynamic crack-propagation in solids and internal defect in a pipe. The EML intensity of nanoparticles is so intense that it is able to drive a solar cell system and it can be used as a light-source for specific applications. Furthermore, several parameters of nanoparticles can be determined from their EML measurements.
\end{abstract}

Keywords: Mechanoluminescence, Triboluminescence, Nanoparticles, $\mathrm{ZnS}: \mathrm{Mn}, \mathrm{SrAl}_{2} \mathrm{O}_{4}: \mathrm{Eu}$.

\section{INTRODUCTION}

Mechanoluminescence (ML) is the phenomenon of light emission from a solid as a response to the mechanical stimulus given to it. In other words, ML is a type of luminescence induced by any mechanical action on solids. ML can by excited by grinding, cutting, cleaving, rubbing, shaking, scratching, compressing, loading, crushing or impulsive deformation of solids. It can also be excited by thermal shocks caused by drastic cooling or heating of materials or by the shock-waves produced during exposure of samples to laser pulses or ultrasonic waves. ML also appears during the deformation caused by the phase-transition or growth of certain crystals as well as during separation of two solids in contact [1]. The physical processes involved in inducing ML in solids indicate that basically there should be two types of ML, namely, deformation ML (DML) and tribo ML (TML). The former is produced owing to the physical process induced during deformation of solids, whereas the latter is produced during the due to the contact phenomena such as triboelec

*Address correspondence to this author at the Department of Applied Physics, Ashoka Institute of Technology and Management, Torankatta,G.E.Road,Rajnandgaon, 491441 (C.G.), India;

Tel: 91-0771-2263650; E-mail: bpchandra4@yahoo.co.in tricity, tribochemical reaction, and tribothermal generation induced contact or separation of two dissimilar materials in contact. DML depends only on the material under deformation and is independent of both the material used to produce the deformation and the contact phenomenon. TML, on the other hand, depends on the nature of the material under deformation as well on the material used to produce it, and arises solely owing to contact phenomena. DML may further be subdivided into three types, namely, elastico ML (EML), plastico ML (PML) and fracto ML (FML), in which, the ML is induced by elastic deformation, plastic deformation, and fracture, respectively. TML may further be subdivided as electrically-induced TML, chemically-induced TML, and thermally -induced TML, in which TML is induced by electrification, chemical reaction and heat production, respectively.

The ML was probability first discovered when human lived in caves, since many common minerals produce very bright light emissions. The first recorded discovery of ML was made by Francis Bacon in 1605, who reported it in his writings, Advancement of Learning, that "hard sugar being nimbly scrapped with a knife would afford a sparkling light". Robert Boyle in 1664 reported that a particular diamond when "pressed on with a steel bodkin produced a very vivid but exceeding short-lived splendor. "Waller in 1684 re- 
ported that when substances such as white sugar, loaf sugar, and salt gemme (rock salt) were crushed in a mortar, they gave such intense light that the sides of the mortar and shape of the pestle could distantly be displayed. By the end of the 1700 s, a number of minerals and pottery materials were known to exhibit ML. Wedgwood in 1792 reported the ML of many substances inducing quartz, diamond and ruby. The observation of light emission associated with the rock failure in mines and earthquakes have been reported for several centuries. To date, ML has been tested in more than one thousand materials, and certain solids have been found to exhibit intense ML. The ML Intensity $\mathrm{SrAl}_{2} \mathrm{O}_{4}: \mathrm{Eu}, \mathrm{ZrO}_{2}: \mathrm{Ti}$, $\mathrm{Ca}_{2} \mathrm{Al}_{2} \mathrm{SiO}_{7}: \mathrm{Ce}$, europium tetrakis (dibenzoyl methide) triethyl ammonium, ditriphenylphosphine oxide manganese bromide, impure saccharin, etc. is so intense that it can be seen in day light with naked eye. The well known examples of tribo ML are the light produced during friction of our body with silky cloth, separation of a tape from the substrate, movement of mercury on luminescent layers. The appearance of tribo ML in adhesives and other polymers has brought it to the attention of mothers using diaper tape, photographers unrolling film and the many users of duct tape. In past, the phenomenon of ML has been reviewed by Meyer et al. [2], Walton [3], Molotskii [4], and Chandra [1], where the history and other details of ML can be obtained.

Whereas nearly $50 \%$ of all inorganic salts and organic molecular solids show ML during their fracture, only a few solids exhibit ML during their elastic and plastic deformation. The examples of intense fracto mechanoluminescent materials are: $\mathrm{SrAl}_{2} \mathrm{O}_{4}: \mathrm{Eu}, \mathrm{SrMgAl}_{6} \mathrm{O}_{11}: \mathrm{Eu}, \mathrm{Ca}_{2} \mathrm{Al}_{2} \mathrm{SiO}_{7}: \mathrm{Ce}$, $\mathrm{ZrO}_{2}: \mathrm{Ti}$, ditriphenyl phosphine oxide manganese bromide, europium tetrakis (dibenzoyl methide) triethyl ammonium, impure saccharin, cholesterol salicylate, $\mathrm{N}$-acetylanthranilic acid, phenanthrene, uranyl nitrate hexahydrate, sucrose, tartaric acid, etc. The examples of elastico mechanoluminescent materials are:, $\mathrm{x}$ or $\gamma$-irradiated alkali halide crystals, $\mathrm{ZnS}: \mathrm{Mn}, \quad \mathrm{SrAl}_{2} \mathrm{O}_{4}: \mathrm{Eu}, \quad \mathrm{SrAl}_{2} \mathrm{O}_{4}$ : $\mathrm{Ce}, \quad \mathrm{SrAl}_{2} \mathrm{O}_{4}: \mathrm{Ce}, \mathrm{Ho}$, $\mathrm{SrAl}_{2} \mathrm{O}_{4}: \mathrm{Er}, \quad \mathrm{SrAl}_{2} \mathrm{O}_{4}: \mathrm{Eu}, \mathrm{Er}, \quad \mathrm{SrMgAl}_{6} \mathrm{O}_{11}: \mathrm{Eu}, \quad \mathrm{SrCaM}-$ $\mathrm{gSi}_{2} \mathrm{O}_{7}: \mathrm{Eu}, \mathrm{SrBaMgSi}_{2} \mathrm{O}_{7}: \mathrm{Eu}, \mathrm{Sr}_{2} \mathrm{MgSi}_{2} \mathrm{O}_{7}: \mathrm{Eu}$,

$\mathrm{Ca}_{2} \mathrm{MgSi}_{2} \mathrm{O}_{7}: \mathrm{Eu}, \mathrm{Dy}, \quad \mathrm{CaYAl}_{3} \mathrm{O}_{7}: \mathrm{Eu},(\mathrm{Ba}, \mathrm{Ca}) \mathrm{TiO}_{3}: \mathrm{Pr}^{3+}$, $\mathrm{ZnGa}_{2} \mathrm{O}_{4}: \mathrm{Mn}, \mathrm{MgGa}_{2} \mathrm{O}_{4}: \mathrm{Mn}, \mathrm{BaAl}_{2} \mathrm{Si}_{2} \mathrm{O}_{8}$ :rare earth element, $\mathrm{BaSi}_{2} \mathrm{O}_{2} \mathrm{~N}_{2}: \mathrm{Eu}^{2+}, \mathrm{Ca}_{2} \mathrm{Al}_{2} \mathrm{SiO}_{7}: \mathrm{Ce}, \mathrm{ZrO}_{2}: \mathrm{Ti}$ and $\mathrm{ZnS}: \mathrm{Mn}$, Te . The rare earth element can be Eu. The elastico ML has also been observed in the nanoparticles of $\mathrm{ZnS}: \mathrm{Mn}, \mathrm{SrAl}_{2} \mathrm{O}_{4}: \mathrm{Eu}$ and $\mathrm{ZnMnTe}$. A few polymers and rubbers have also been reported to be elastico mechanoluminescent.In addition to all the elastico mechanoluminescent materials mentioned above, alkaline earth oxides, certain non-coloured alkali halide crystals, certain varieties of rubber and certain metals also exhibit plastico ML. To date, most studies of ML have been made on $\mathrm{x}$ or $\gamma$-irradiated alkali halide crystals. II-VI semiconductors, sugar crystals and $\mathrm{SrAl}_{2} \mathrm{O}_{4}$ :Eu phosphors [1-6].

Although the phenomenon of ML is known for a long time, in the past no practical application could be made because of the low ML intensity of the materials and lack of reproducibility. In the recent past, systematic material researches have been done and they have resulted in producing a variety of materials that emit an intensive and repeatable ML during their elastic deformation without any destruction. Among these materials are: $\mathrm{ZnS}: \mathrm{Mn}, \mathrm{MAl}_{2} \mathrm{O}_{4}: \operatorname{Re}(\mathrm{M}=$ alkaline materials, $\mathrm{Re}=$ rare earth metals) and $\mathrm{SrMgAl}_{10} \mathrm{O}_{17}: \mathrm{Eu}$.
So far the most promising elastico mechanoluminescent materials are rare-earth doped alkaline aluminates and the transition metal ion doped zinc sulphide. In recent years, significant experimental studies have been made and remarkable upgrading in the intensity of elastico ML has been achieved in the $\mathrm{SrAl}_{2} \mathrm{O}_{4}$ doped with europium by controlling the lattice defects in the material [6-18]. Significant enhancement in the EML intensity of $\mathrm{ZnS}: \mathrm{Mn}$ nanocrystals has also been achieved by improving their crystallinity [19-24]. Rare earth doped strontium aluminate phosphors have been found useful in the real-time visualizations of stress distribution in solids [6, 25], stress field near crack-tip [26], and quasidynamic crack-propagation in solids [27-29]. Xu. et al. [19] have explored the idea and developed a successful practice of a stress sensor by an artificial skin, that is, self-diagnosis thin film has been realized through the fabrication of a high luminescent thin piezoelectric film of $\mathrm{ZnS}: \mathrm{Mn}$ nanoparticles, which can reproducibly emit strong visible light upon stressing. The nanoparticles of $\mathrm{SrAl}_{2} \mathrm{O}_{4}: \mathrm{Eu}$, Dy have also been reported to exhibit intense ML [30, 31], Reddy et al. have reported intense ML from ZnMnTe nanoparticles [32].Chandra et al. [24] have studied the dependence of the EML of nanoparticles on different parameters.

As the ML intensity of certain nanoparticles is higher as compared to that of the bulk, and moreover, smaller size of crystals in composite or in ML paints may provide high space resolution in imaging the stress distribution in solids, the study of the elastico ML of nanoparticles is interesting and useful. The present paper reviews the experimental works on the ML induced by the elastic deformation of $\mathrm{ZnS}: \mathrm{Mn}$ and $\mathrm{SrAl}_{2} \mathrm{O}_{4}$ :Eu nanoparticles,describes the mechanisms and explores the theory of the elastico ML,whereby a good agreement is found between the experimental and theoretical results. Furthermore, the importance of the elastico ML of nanoparticles is discussed in detail.

\section{EXPERIMENTAL}

\subsection{Preparation of $\mathrm{ZnS}:$ Mn Nanoparticles}

The film of $\mathrm{ZnS}: \mathrm{Mn}$ nanoparticles was prepared by $\mathrm{Xu}$ et al. on various substrates by physical vapour deposition of ion plating or a sputtering method $[19,20]$. The source material of $\mathrm{ZnS}: \mathrm{Mn}$ was pretreated at $1050^{\circ} \mathrm{C}$ for $3 \mathrm{~h}$ in a vacuum sealed quartz tube before deposition. A highly oriented film was achieved by selecting a deposition rate of $2 \mathrm{~nm} / \mathrm{s}$ and a substrate temperature of $160^{\circ} \mathrm{C}$. The chemical composition determined by X-ray diffraction pattern showed that the Mn amount in the film was the same as in the source material, i.e., 1.5 percent. Moreover, the X-ray diffraction pattern showed only one strong diffraction peak at $28.49^{\circ}$ in the $2 \theta$ range of $10^{\circ}-90^{\circ}$, which was attributed to the (111) plane of $\mathrm{ZnS}$, indicating that the film was highly oriented. Fig. (1) shows the highly oriented $\mathrm{ZnS}: \mathrm{Mn}$ film observed by field emission scanning electron microscope (FE-SEM). The field emission scanning electron microscope and XRD techniques indicate that the $\mathrm{ZnS}: \mathrm{Mn}$ film was composed of nano-sized crystallites with a mean size of $20 \mathrm{~nm}$.

\subsection{Preparation of $\mathrm{SrAl}_{2} \mathrm{O}_{4}: \mathrm{Eu}$, Nanoparticles}

The nanoparticles of $\mathrm{SrAl}_{2} \mathrm{O}_{4}$ :Eu can be the synthesized using ultrasonic pyrolysis technique[30]. The ultrasonic 


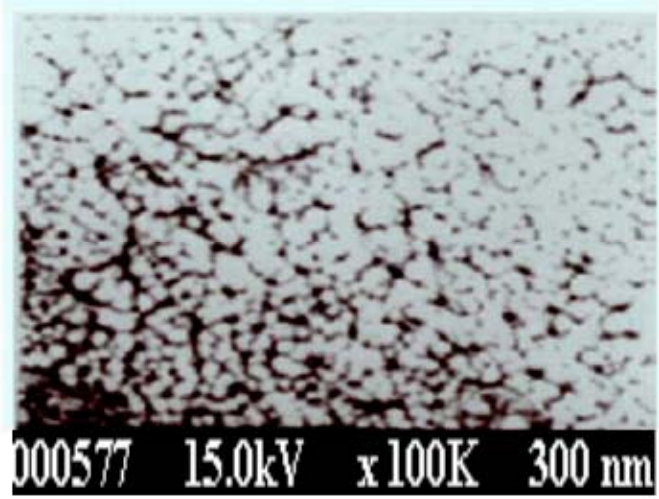

Fig. (1). FE-SEM surface image of the $\mathrm{ZnS}: \mathrm{Mn}$ thin film on glass (after Xu. et al. ref. [20]).

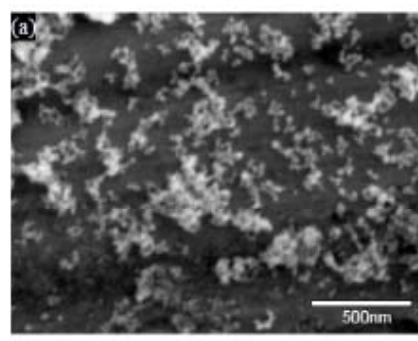

(a)

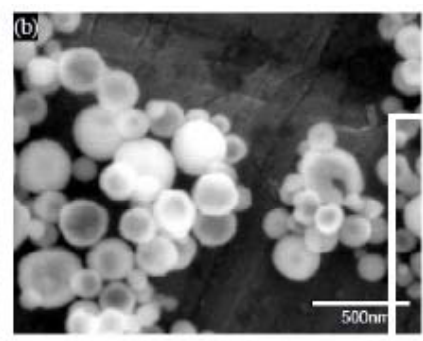

(b)
Fig. (2). FE-SEM observation of the as-prepared particles prepared by ultrasonic pyrolysis method (a) compared with that prepared by the conventional process (b) ( after Xu et al., ref.[30]).

spray pyrolysis system used consisted of an ultrasonic atomizer with $2.4 \mathrm{MHz}$ transducer, a horizontal reaction furnace, and an electrostatic precipitator. Strontium acetylacetonate, aluminum acetylacetonate and europium acetylacetonate were dissolved in deionized water containing desired amount of the organic solvents to prepare a starting solution. The starting solution was atomized and the mist and water were carried into the furnace tube by a $5 \% \mathrm{H}_{2} / \mathrm{Ar}$ carrier gas. The carrier gas speed was maintained at $2 \mathrm{~L} / \mathrm{m}$ and the furnace temperature was $1300{ }^{\circ} \mathrm{C}$. A conventional ultrasonic spray pyrolysis was carried out using an aqueous solution of metal nitrates as the starting solution. The nanoparticles of $\mathrm{SrAl}_{2} \mathrm{O}_{4}$ : Eu can also can be prepared using polymer-coated precursor [31].The morphology and particle size of the sample were determined using field emission microscopy and transmission electron microscopy. The crystal-structure was determined by X-ray diffraction (XRD). Fig. (2) shows the FE-SEM image of the nanoparticles prepared by the ultrasonic pyrolysis method using organic compounds as starting materials, and for comparison. Fig. (2b) shows the morphology of the sub-micrometer sized particles prepared by a conventional ultrasonic spray pyrolysis of nitrate salts. Fig. (3) shows the TEM image and electron distribution pattern of the as-prepared nanoparticles. The size of the nanoparticles was in the range of $10 \mathrm{~nm}$ to $30 \mathrm{~nm}$. The crystal-structure of the as-prepared particle was $\alpha-\mathrm{SrAl}_{2} \mathrm{O}_{4}: \mathrm{Eu}$.

\subsection{Measurement of EML}

In ML phenomenon, mechanical energy is given to the system and consequently, the light emission takes place.

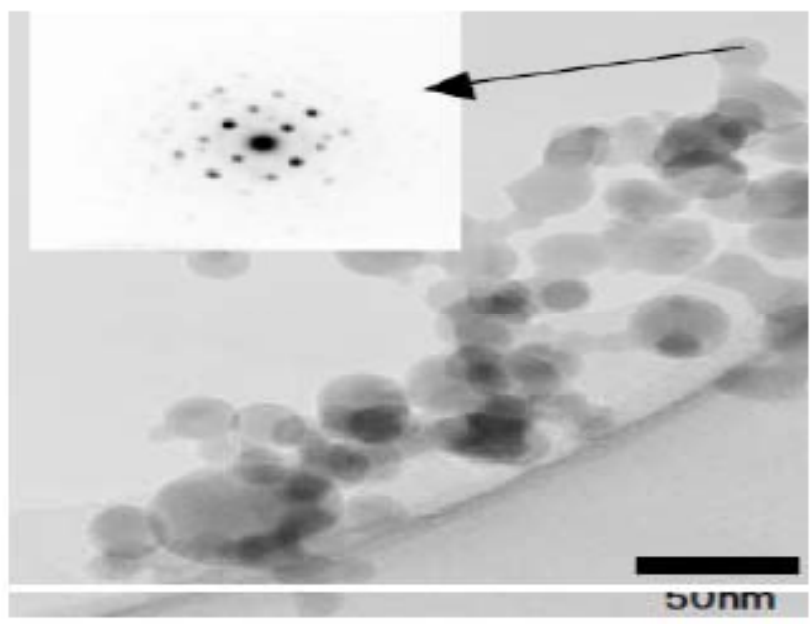

Fig. (3). TEM image and electron diffraction pattern of the asprepared nanoparticles (after Xu et al., ref. [30]).

Thus, the ML measurements require the mechanical devices as well as optical devices. In the past, several techniques have been used ,for examples, compression, bending, stretching, loading, piston impact, needle impact, cleaving and cutting, shaking, air-blast, stretching, grinding, milling, laser-shocks, ultrasonic- shocks, thermal -shocks, rubbing, separation of two solids in contact ,etc. [1]. Material testing machine has been found suitable for exciting the ML in solids. Fig. (4) gives the measurement devices for nondestructive ML, whereby the ML measurements can be done by compression, tension, bending and shearing of the samples. Fig. (4a) illustrates the schematic diagram of $\mathrm{ML}$ measurement device, whereby the simultaneous measurements of the ML-strain and stress-strain curves can be obtained. In this case, stress is applied on to the samples by the cross -head of the testing machine and the ML intensity is measured by a photon-counting system that consists of a photomultiplier tube and a photon counter controlled by a computer. In these measurements, the light emitted due to ML is guided to the photomultiplier through a quartz glass fiber. The ML spectra are recorded using a photon multichannel analyzer system. The ML images are obtained using an image intensified charge coupled device (ICCD) controlled by a computer system .Simultaneously the stress and strain of the samples can be measured by stress sensor, and strain sensor. In addition to compression test, the material testing machine can be used for tensile and bending by exchanging the sample holder.

Fig. (4b) shows the schematic diagram of the device where the ML in a sample can be excited by impact of a freefalling ball through a pipe, in which impact velocity can be adjusted by changing the height through which the ball is dropped and the impact energy can be adjusted by changing the weight of the ball and the height through which the ball is dropped.

Fig. (4c) illustrates the schematic diagram of ML measurement device for applying friction (shear stress), in which the same instruments as shown in Fig. (4a) can be used for measuring the ML intensity and spectra. In this case, the mechanical friction is applied by a friction rod under a load. The friction rod material and the load can be changed for 


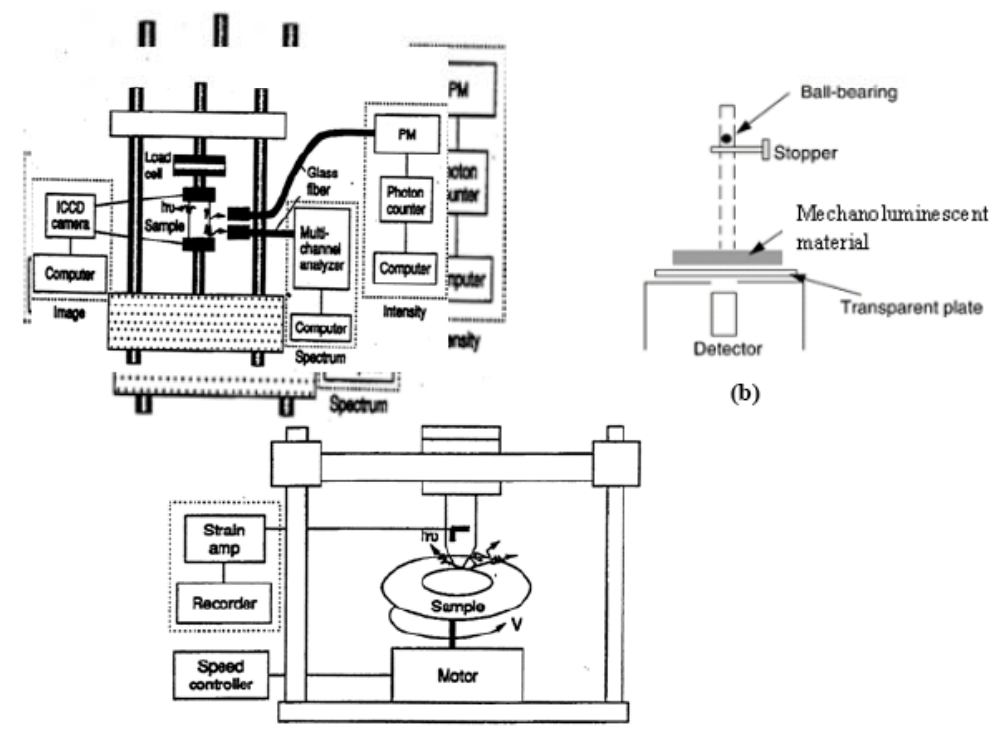

(c)

Fig. (4). Schematic diagram of the devices used for EML measurements: (a) a material testing machine for inducing EML by compression (after Xu. ref. [6]), (b) impulsive deformation technique for inducing EML, and (c) friction technique for inducing tribo ML (after Xu. ref. $[6])$.

different levels of mechanical stress applied to the test material .As the material is rotated at a controlled speed, as shown in Fig. (4c), the friction rod draws a concentric circle on the test material. The light emitted due to the ML caused by friction is guided to the photomultiplier tube through a quartz glass fiber that is $3 \mathrm{~mm}$ in diameter whereby the distance between the glass fiber and the friction tip was set to $40 \mathrm{~mm}$.

The elastico ML behavior of $\mathrm{SrAl}_{2} \mathrm{O}_{4}$ : Eu single particles can be investigated by using an atomic force microscopy (AFM) equipped with a photon counting system controlled by a computer [30]. For studying the pressure dependence of the elastico $\mathrm{ML}$ of $\mathrm{SrAl}_{2} \mathrm{O}_{4}$ :Eu nanoparticles, a molding which had a diameter of $25 \mathrm{~mm}$ and a thickness of $10 \mathrm{~mm}^{2}$ was made by mixing $0.2 \mathrm{~g}$ of nanophosphors with $4.0 \mathrm{~g}$ of epoxy resin of epichlorohydrine and by pressing the sample using a power press machine with a force gauge [31]. The elastico ML was induced by a time-variant compressive load using a material testing machine. The ML intensity was measured by a photon counting system, and the ML spectra were recorded using a spectrometer attached to a photonic multichannel analyzer.

\section{MECHANISMS OF THE EML OF NANOPARTI- CLES}

\subsection{Mechanism of the EML of $\mathrm{ZnS}$ :Mn Nanoparticles}

As $\mathrm{ZnS}$ crystals is non-centrosymmetric [33], the piezoelectrifiction caused by elastic deformation may give rise to the light emission [19, 34-38]. The other possibility for the occurrence of ML in $\mathrm{ZnS}: \mathrm{Mn}$ crystals may be the electrostatic interaction between charged dislocations and filled electrons traps [1, 4, 39-43]. The dislocation model has been found to be suitable for the plastico ML of II-VI semiconductors [1]. It is to be noted that thermodynamic analysis suggests that dislocations and stacking faults should be un- stable in nanoparticles with respect to diffusion to the surface and annihilation. However, such defects may be retained by kinetic factors; for example, association with large scale shape features derived from the assembly of smaller nanoparticles precursors [44-47], or be trapped at nanoparticles grain boundaries. The existence of dislocations in $\mathrm{ZnS}$ nanoparticles has also been reported $[48,49]$. The following experimental facts support the suitability of piezoelectrically-induced electron detrapping model for the elastico ML in $\mathrm{ZnS}: \mathrm{Mn}$ nanoparticles [24].

(i). $\quad \mathrm{ZnS}$ crystal possesses non-centrosymmetric structure [33], hence, piezoelectric origin of elastico ML may be possible.

(ii). The waveforms of ML induced by application of load, release of load, and impulsive deformation of $\mathrm{ZnS}: \mathrm{Mn}$ crystals are similar to the waveforms of the piezoelectric charges produced during application of load, release of load, and impulsive deformation, respectively $[19,50]$.

(iii). In dislocation electrostatic interaction model of elastico ML, the bending of dislocation segments causes the ML excitation, in which the total ML emission increases linearly with the stress because the bending increases linearly with stress [51]. In piezoelectrically-induced electron detrapping model, electrical energy which depends on the mechanical energy is responsible for the ML excitation. As the mechanical energy, hence, the stress-induced electrical energy depends quadratically on the stress, the total ML emission depends quadratically on the applied stress. Practically, the total emission from elastico ML of $\mathrm{ZnS}: \mathrm{Mn}$ nanocrystals depends quadratically on the applied stress, [19], hence, this results supports the piezoelectric origin of the elastico ML of $\mathrm{ZnS}: \mathrm{Mn}$ nanocrystals. 


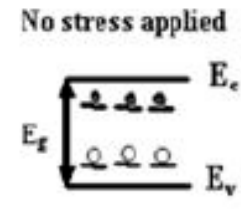

(i)

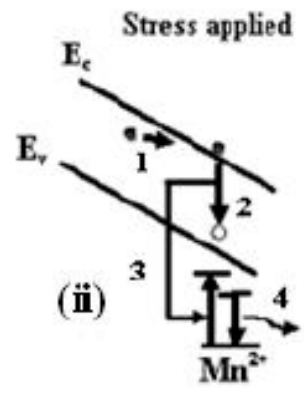

Fig. (5). Schematic diagram for the EML emission in $\mathrm{ZnS}: \mathrm{Mn}$ nanoparticles(1-detrapping of electron and its movement in conduction band, 2-electron-hole recombination, 3- transfer of energy to $\mathrm{Mn}^{2+}$, ion and excitation of $\mathrm{Mn}^{2+}$ ion, and 4- emission of light).

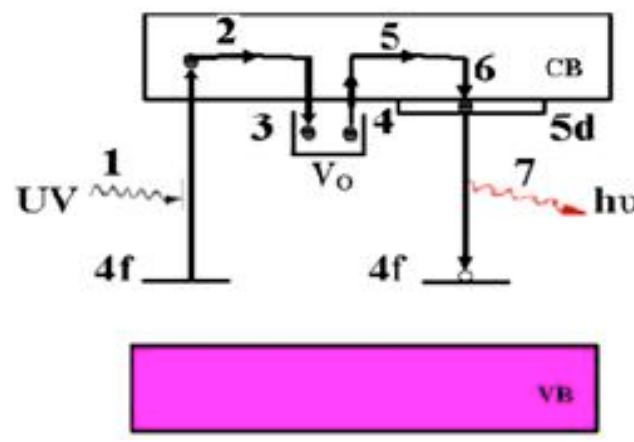

Fig. (6). Schematic diagram for the EML in $\mathrm{SrAl}_{2} \mathrm{O}_{4}$ :Eu nanoparticles (1-excitation of $\mathrm{Eu}^{2+}$, 2- electron movement in $\mathrm{CB}$, 3-electron trapping, 4-electron release, 5-electron movement in $\mathrm{CB}$, 6electron-capture at $5 \mathrm{~d}$ of $\mathrm{Eu}^{2+}$, and 7- light-emission).

(iv). When the plastico ML including elastico ML of $\mathrm{ZnS}: \mathrm{Mn}$ crystals is induced by application of hydrostatic pressure, then intense ML emission is observed [52]. As the dislocations cannot move under hydrostatic pressure [53], the part of plastico ML and elastico ML induced by moving dislocations is suppressed, and the observed ML emission may be attributed to the piezoelectrically -induced plastico ML and elastico ML.

The piezoelectric constant $\mathrm{d}_{33}$ of $\mathrm{ZnS}$ crystal is $3.3 \times 10^{-11}$ Coulomb Newton $^{-1}$ [54]. In the elastic region, the ML emission in $\mathrm{ZnS}: \mathrm{Mn}$ starts nearly at $1 \mathrm{MPa}\left(=10^{6}\right.$ Newton meter ${ }^{2}$ ). Thus, the piezoelectric charge density will be, $\rho=3.3 \mathrm{x}$ $10^{-11} \times 10^{-6}=3.3 \times 10^{-5}$ Coulomb meter ${ }^{-2}$. The electric field developed near the surface of crystal will be, $F=\rho / \varepsilon_{0}$, that is, $\mathrm{F}=3.7 \times 10^{6} \mathrm{Vm}^{-1}=3.7 \times 10^{4} \mathrm{~V} \mathrm{~cm}^{-1}$, where $\varepsilon_{0}=8.85 \mathrm{x}$ $10^{-12}$ Coulomb Newton meter ${ }^{-2}$, is the permittivity of the space. The dielectric constant of $\mathrm{ZnS}$ crystals is 8.8 , hence, the internal electric field will be nearly one order less as compared to the external field on surface of crystals, but the luminescence measurement is generally made in terms of the external field at the surface of the sample. The piezoelectric field of the order of $3 \times 10^{4} \mathrm{Vcm}^{-1}$ is not able to cause detrapping of electrons from traps and also it may not cause the impact excitation of $\mathrm{Mn}^{+2}$ centres, where an electric field of the order of $10^{6} \mathrm{Vcm}^{-1}$, is needed. The appearance of elastico $\mathrm{ML}$ in $\mathrm{ZnS}: \mathrm{Mn}$ nanocrystals indicates that the local electric field near $\mathrm{Mn}^{2+}$ ions should be higher because of the local change in the crystals structure near $\mathrm{Mn}^{2+}$ sites, where the piezoelectric constant should be higher. The change in the local structure near the impurities has been reported by many workers $[55,56]$ and the possibility of the higher piezoelectric constant near the impurity centres has also been reported $[34,35]$. If there is nearly 3 to 4 times increase in the piezoelectric constant near the $\mathrm{Mn}^{2+}$ centres, then the electric field of the order of $10^{5} \mathrm{Vcm}^{-1}$ may be produced, which may cause sufficient decrease in the trap-depth and subsequent electron-hole recombination may release energy nonradiatively for the excitation of $\mathrm{Mn}^{2+}$ centres. It is to be noted that the electric field of the order of $10^{5} \mathrm{Vcm}^{-1}$, may not cause the impact excitation of $\mathrm{Mn}^{2+}$ centres. The crystals of $\mathrm{ZnS}: \mathrm{Cu}$ and $\mathrm{ZnS}: \mathrm{Ag}$ do not show elastico ML because the local piezoelectrification near $\mathrm{Cu}$ and $\mathrm{Ag}$ centres may not be sufficient for causing the detrapping of electrons from the filled electrons traps. Although, in the past many workers [6,19,34-38] have reported the piezoelectric origin of ML, primarily on the basis of the similarity between the waveforms, spectra, temperature dependence and other characteristics of ML and EL, no attempt has been made regarding the field ionization of traps and impact excitation or ionizations of luminescence centres under internal piezoelectric field. Chudacek [34] has reported that the piezoelectric field produced by the deformations of $\mathrm{ZnS}$ crystals is less to cause ML, and he has suggested that the local piezoelectric filled near the defect centres may be higher and it may produce ML.

Fig. (5) shows the schematic diagram for the EML emission in ZnS:Mn crystals. The mechanism of the elastico ML in $\mathrm{ZnS}: \mathrm{Mn}$ nanoparticles may be understood in the following way:

(i). The deformation of ZnS:Mn nanocrystals produces piezoelectric field because crystal - structure of $\mathrm{ZnS}$ is non-centrosymmetric [33].

(ii). Because of the decrease in the trap-depth due to the piezoelectric field, the detrapping of electrons from filled-electron traps takes place, and therefore, electrons reach the conduction band.

(iii). The electrons reaching the conduction band may recombine with the holes trapped in the defect centres or they may jump to the valence band and subsequently energy may be released non-radiatively.

(iv). The energy released non-radiatively during electronhole recombination may be transferred to the $\mathrm{Mn}^{2+}$ ions, whereby $\mathrm{Mn}^{2+}$ ions may get excited [57-60].

(v). The de-excitation of excited. $\mathrm{Mn}^{2+}$ ions gives rise to the light emission characteristic of the $\mathrm{Mn}^{2+}$ ions.

(vi). As the piezoelectric field is also produced during the release of pressure, the ML may also be produced when the pressure is released from ZnS:Mn thin film. Therefore, the mechanism of the occurrence of ML during the release of pressure should be similar to that for the application of pressure.

\subsection{Mechanism of the EML of $\mathrm{SrAl}_{2} \mathrm{O}_{4}$ : Eu Nanoparti- cles}

The appearance of ML only in the piezoelectric- phase of strontium aluminate phosphors indicates that the piezoelectrification is responsible for the $\mathrm{ML}$ of $\mathrm{SrAl}_{2} \mathrm{O}_{4}: \mathrm{Eu}$ [10]. Fig. (6) shows the schematic diagram for the EML emission in 


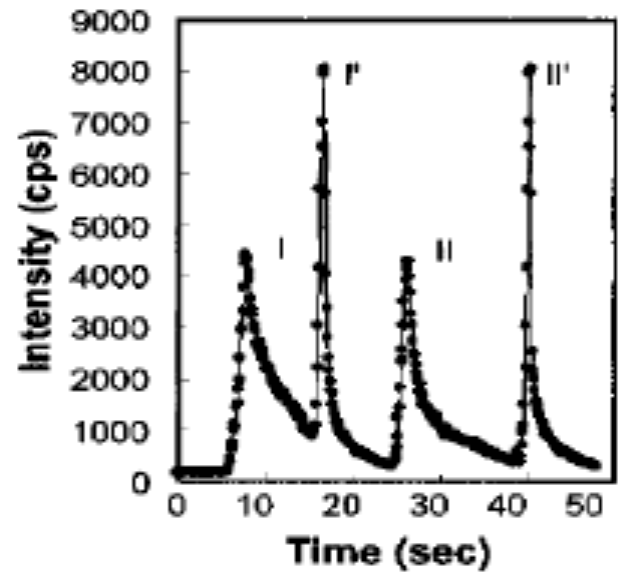

Fig. (7). EML response of ZnS:Mn nanoparticles coated on quartz plate for the compression stress of $500 \mathrm{~N}$, which was applied by material testing machine with a cross-head speed of $0.10 \mathrm{~mm} / \mathrm{min}$. (after Xu et al. ref.[19].

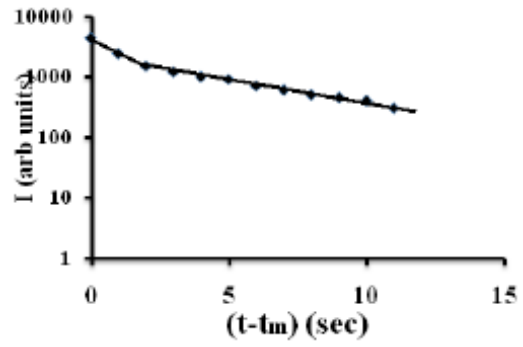

Fig. (8). Plot of $\ln I$ versus ( $\left(t-t_{m}\right)$ for $\mathrm{ZnS}: \mathrm{Mn}$ nanoparticles for the EML induced by application of pressure of $500 \mathrm{~N}$.

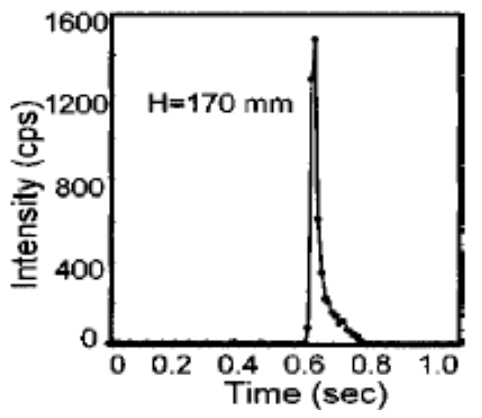

Fig. (9). ML response of the ZnS:Mn nanoparticles coated on a quartz plate to an impact stress applied by a free- falling steel ball from a height of $170 \mathrm{~mm}$ (after Xu et al., ref. [19]).

$\mathrm{SrAl}_{2} \mathrm{O}_{4}: \mathrm{Eu}$ crystals. The steps involved in the ML emission in $\mathrm{SrAl}_{2} \mathrm{O}_{4}$ : Eu nanoparticles are as given below:

(i). The application of pressure produces piezoelectric field in $\mathrm{SrAl}_{2} \mathrm{O}_{4}: \mathrm{Eu}$ crystals because they are noncentrosymmetric [10] in which the piezoelectric field near certain defects centres may be high due to the change in the local structure.

(ii). The piezoelectric field reduces the trap-depth of the carriers.

(iii). The decrease in trap- depth causes transfer of electrons from electron traps to the conduction band.

(iv). Subsequently, the moving electrons in the conduction band are captured in the excited state of $\mathrm{Eu}^{2+}$ ions lo-

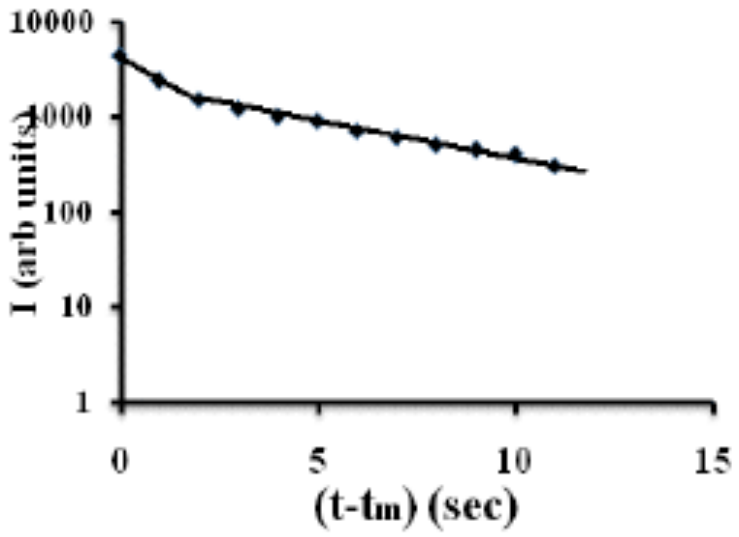

Fig. (10). Plot of $\log \mathrm{I}$ versus $\left(\mathrm{t}-\mathrm{t}_{\mathrm{m}}\right)$ for $\mathrm{ZnS}: \mathrm{Mn}$ nanoparticles coated on a quartz plate.

cated at the bottom of the conduction band, whereby excited $\left(\mathrm{Eu}^{+2}\right)$ ions are produced [61-63].

(v). The de-excitation of $\left(\mathrm{Eu}^{2+}\right)^{*}$ ions gives rise to the light emission characteristic of the $\left(\mathrm{Eu}^{2+}\right)$ ions.

\section{EXPERIMENTAL RESULTS ON THE ELASTICO ML OF NANOPARTICLES}

\subsection{Elastico ML of ZnS: Mn Nanoparticles}

Fig. (7) shows that when a load is applied on to the $\mathrm{ZnS}: \mathrm{Mn}$ nanoparticles film coated on to a quartz substrate, then initially the EML intensity increases with time, attains a peak value and later on it decreases with time [19]. It is seen that when pressure is released, then the EML emission also takes place. It is evident from Fig. (7) that when the load is applied for the second time, then also the EML emission takes place during the application and release of the applied pressure. This fact shows the reproducibility of EML. Corresponding to the application and release of pressure, two EML pulses $I_{\text {and }} \mathrm{I}^{\mathrm{I}}$, respectively are generated during one cycle of the applied pressure, and all of which were reproducible as shown in II and II ${ }^{\prime}$ in Fig. (7) The threshold pressure for the appearance of EML in $\mathrm{ZnS}: \mathrm{Mn}$ nanoparticles is nearly equal to $1 \mathrm{MPa}$. Fig. (8) shows the plot between the $\log$ of EML intensity I and $\left(\mathrm{t}-\mathrm{t}_{\mathrm{m}}\right)$. From Fig. (8), the fast and slow decay times of EML are found to be 1.69 and $5.88 \mathrm{sec}$, respectively. The plot between $\log I$ and $\left(t-t_{m r}\right)$ for the EML induced by release of pressure, is also similar to Fig. (8) (where $t_{m r}$ is the time corresponding to the peak of ML intensity versus time curve for the case of release of pressure). However, in this case, the value of slope is higher because the release of pressure was performed at higher rate.

Fig. (9) shows that when a small load is dropped on to $\mathrm{ZnS}: \mathrm{Mn}$ nanoparticles film from a low height, then initially the ML intensity increases linearly with time, attains a peak value and later on it decreases with time [19]. Fig. (10) illustrates that, in this case also, the plot between $\log I$ and $\left(t-t_{m}\right)$, is straight line with a negative slope. Fig. (11) illustrates the dependence of the EML intensity of $\mathrm{ZnS}: \mathrm{Mn}$ nanoparticles on the falling height of a steel ball. It is evident that both $\mathrm{I}_{\mathrm{m}}$ and $\mathrm{I}_{\mathrm{T}}$ increase with increasing value of the height through which the ball is dropped on to the nanoparticles. The values of the fast and slow decay times for the EML excited by the 


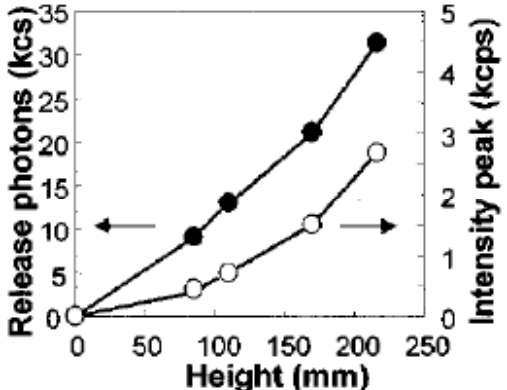

Fig. (11). Dependence of the ML intensity of ZnS:Mn nanoparticles on the falling height of a steel ball(after Xu et al. ref.[20]).

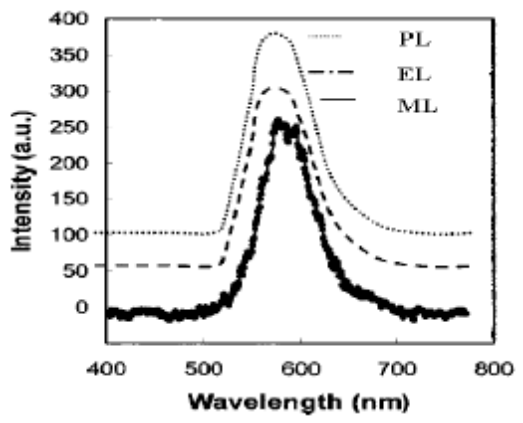

Fig. (12). Spectra of mechanoluminescence (ML), photoluminescence (PL), and electroluminescence (EL) for $\mathrm{ZnS}: \mathrm{Mn}$ nanoparticles(after Xu et al. ref.[20].

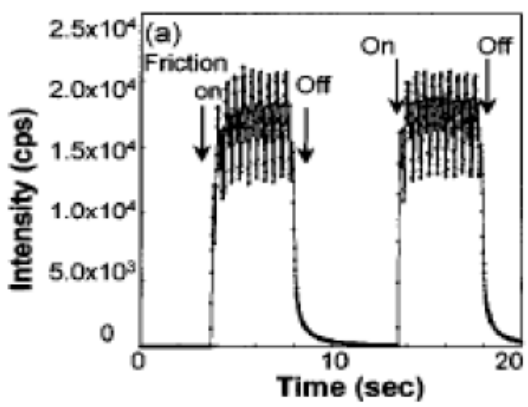

Fig. (13). Triboluminescence intensity response of $\mathrm{ZnS}$ : Mn film to the mechanical friction with a plastic rod of $5 \mathrm{~mm}$ diameter under $5 \mathrm{~N}$ load, and $130 \mathrm{rpm}$ speed,(after Xu et al., ref. [19]).

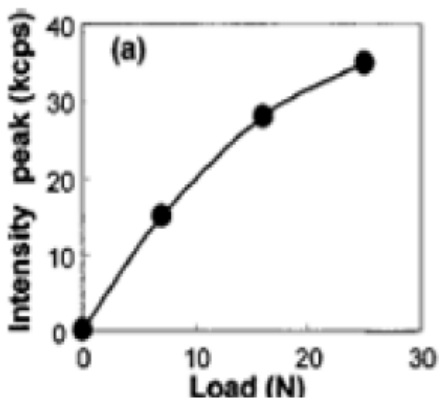

Fig. (14). Dependence of the Triboluminescence intensity on load in the case of friction (after Xu et al., ref. [19]).

impact stress (Fig. 10) come out to be 34.4 and $189 \mu$ sec, respectively.

Fig. (12) shows that, the ML spectra of $\mathrm{ZnS}$ :Mn nanoparticles are similar to their photoluminescence and electroluminescence spectra. The peak of the luminescence spectra

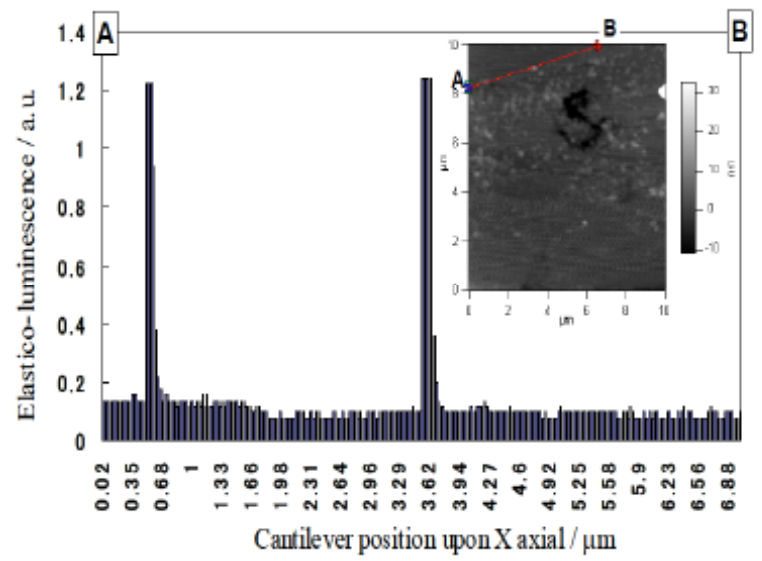

Fig. (15). Elastico mechanoluminescence of $\mathrm{SrAl}_{2} \mathrm{O}_{4}: \mathrm{Eu}$ single nanoparticles measured by AFM/photon-counting system (after Xu et al., ref. [30]).

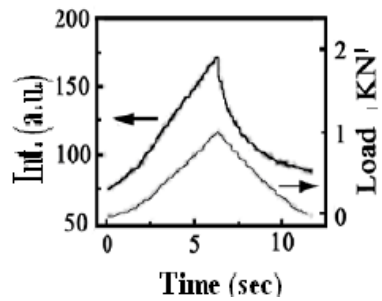

Fig. (16). EML versus compression time, and force versus compression time curves of $\mathrm{SrAl}_{2} \mathrm{O}_{4}:$ Eu nanoparticles mixed in epoxy resin(after $\mathrm{Li}$ et al., ref.[31]).4.2. Elastico ML of $\mathrm{SrAl}_{2} \mathrm{O}_{4}: \mathrm{Eu}$ nanoparticles.

lies at $580 \mathrm{~nm}$, which can be attributed to ${ }^{4} \mathrm{~T}_{1} \rightarrow{ }^{6} \mathrm{~A}_{1}$ transition of $\mathrm{Mn}^{2+}$ ions [19].

Fig. (13) shows the ML intensity response of the $\mathrm{ZnS}: \mathrm{Mn}$ film to the friction using a plastic rod of $5 \mathrm{~mm}$ diameter which was made to rotate on the sample surface at a speed of $130 \mathrm{rpm}$, under $5 \mathrm{~N}$ load. Fig. (14) shows that the intensity of tribo ML of $\mathrm{ZnS}: \mathrm{Mn}$ thin film increases with increasing value of the load applied on to the rotating rod [19]. The tribo ML of $\mathrm{ZnS}: \mathrm{Mn}$ nanoparticles may be due the triboelectrification and /or piezoelectrification.

$\mathrm{Xu}$. et al., [19] have reported that the EML intensity of $\mathrm{ZnS}: \mathrm{Mn}$ nanoparticles is higher as compared to that of the bulk. As the efficiency of the photoluminescence of $\mathrm{ZnS}: \mathrm{Mn}$ nanoparticles is higher as compared to that of the bulk, an increase in the EML intensity is expected with reducing size of the nanoparticles. In addition, the change in other factors of nanocrystalline form as compared to those in bulk may also be responsible for the higher EML intensity of $\mathrm{ZnS}: \mathrm{Mn}$ nanoparticles.

The elastico ML of single nanoparticles of $\mathrm{SrAl}_{2} \mathrm{O}_{4}: \mathrm{Eu}$ has been measured using AFM, whereby a proper stress in the specified single particle was applied [30]. Fig. (15) shows the elastico ML emitted by single nanoparticle. In this technique, a cantilever moved along the straight line $(\mathrm{A} \rightarrow \mathrm{B})$ and the particles in the line were compressed in turn. At the same time, the EML signals generated were collected by a photon counting system. The EML signals were obtained at the moment that the cantilever moved to the nanoparticles and compressed them. 


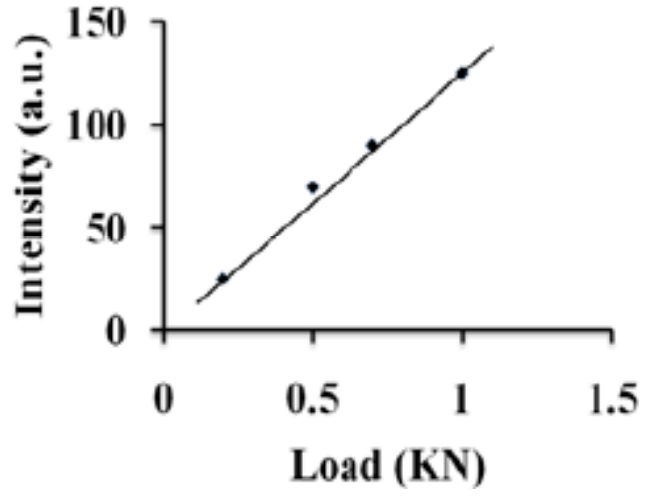

Fig. (17). Dependence of EML intensity on the applied load (plotted on the basis of the data given in Fig.16).

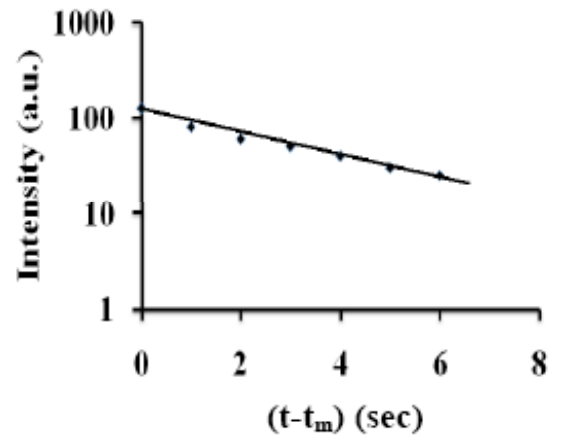

Fig. (18). Plot of $\log \mathrm{I}$ versus $\left(\mathrm{t}-\mathrm{t}_{\mathrm{m}}\right)$ for $\mathrm{SrAl}_{2} \mathrm{O}_{4}$ : Eu nanoparticles. mixed in epoxy resin.

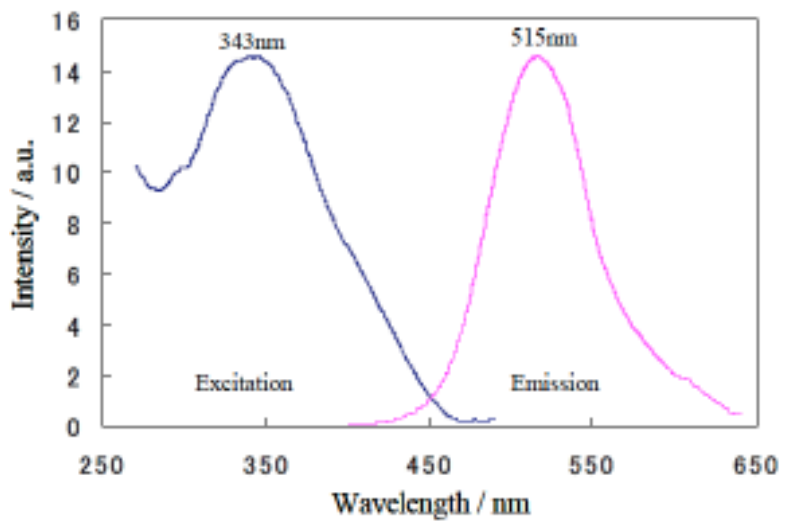

Fig. (19). Excitation and emission spectra of $\mathrm{SrAl}_{2} \mathrm{O}_{4}$ :Eu nanoparticles (after Xu et al., ref [30].

Fig. (16) illustrates a typical ML response curve of elastico ML of $\mathrm{SrAl}_{2} \mathrm{O}_{4}$ :Eu nanoparticles [31]. It is seen that the ML intensity increases with the increase of applied load, showing a maximum value at peak load. Fig. (17) shows that the EML intensity increases linearly with the load applied on the nanoparticles Fig. (18) shows the plot of $\log I$ versus $(t-$ $t_{m}$ ) for $\mathrm{SrAl}_{2} \mathrm{O}_{4}$ : Eu nanoparticles. It is seen that the plot is a straight line with a negative slope. From Fig. (18), the value of the decay time of EML is found to be $3.75 \mathrm{sec}$. The value of the threshold pressure for the EML is very small for $\mathrm{SrAl}_{2} \mathrm{O}_{4}$ : $\mathrm{Eu}$ nanoparticles and it lies in the range of 0.10 $\mathrm{MPa}$.

Fig. (19) shows the excitation and emission spectra of $\mathrm{SrAl}_{2} \mathrm{O}_{4}: \mathrm{Eu}$ nanoparticles [30]. The excitation spectrum has a broad band from $270 \mathrm{~nm}$ to $400 \mathrm{~nm}$ and the peak shifted to the blue side compared with a standard sample prepared by solids-state reaction process. The EMLspectrum possesses a symmetrical band peaked at $515 \mathrm{~nm}$ which can be attributed to the $4 \mathrm{f}^{6} 5 \mathrm{~d}^{1}$ to $4 \mathrm{f}^{7}$ transition of divalent europium.

\section{THEORETICAL APPROACH TO THE ELASTICO ML OF NANOPARTICLES}

In the presence of the piezoelectric field the detrapping of charge carriers may take place either due to tunneling process or due to the thermal ionization of traps owing to the reduction in trap-depth caused by the piezoelectric field. If $\mathrm{N}_{\mathrm{c}}$ is the total number of crystallites in the sample, $\mathrm{N}_{\mathrm{l}}$ is the number of effective defect centres in a nanocrystallite, $\Omega$ is the activation volume near an effective defect centre, that is, at the centre at which the piezoelectric field is high, and $\mathrm{N}_{\mathrm{t}}$ is the concentration of filled electron traps, then the total number of detrapable traps is $n_{t 0}=\Omega N_{c} N_{l} N_{t}$. If $d_{0}$ is the local piezoelectric constant near the effective defect centres, then for the applied pressure $P$, the piezoelectric charge $Q$ near the effective defect centres is given by, $Q=\mathrm{d}_{0} \mathrm{P}$. If the crystal is compressed at a fixed pressing rate $\dot{P}$ or strain rate $\boldsymbol{\varepsilon}$, then in the elastic region $\mathrm{Q}$ is given by

$Q=d_{0} P=d_{0} \dot{P} t=d_{0} Y \dot{\varepsilon} t$

where Y is the Young's modulus of the elasticity of the crystal.

If $F_{c}$ is the characteristic piezoelectric field, that is, the field needed for reducing $\mathrm{n}_{\mathrm{t} 0}$ to $\mathrm{n}_{\mathrm{to}} / \mathrm{e}$ caused by the detrapping of the filled electrons traps in nanocrystals, then we can write the following equation

$-\frac{d n_{t}}{d F}=\frac{n_{t}}{F_{c}}=Z n_{t}$

where $\mathrm{F}$ is the piezoelectric field near effective defect ions, $\mathrm{n}_{\mathrm{t}}$ is the number of filled electron traps at any time $\mathrm{t}$ and $\mathrm{Z}=$ $1 / \mathrm{F}_{\mathrm{c}}$.

Integrating Eq. (2) and taking $\mathrm{n}_{\mathrm{t}}=\mathrm{n}_{\mathrm{t} 0}$, for the threshold field $\mathrm{F}=\mathrm{F}_{\mathrm{th}}$, we get

$n_{t}=n_{t 0} \exp \left[-Z\left(F-F_{t h}\right)\right]$

where $\mathrm{n}_{\mathrm{t} 0}$ is the total number of the filled electron traps in the activation volume $\Omega \mathrm{N}_{1}$.

Using Eq. (3), the total number of detrapped electrons can be expressed as

$n_{d}=\left(n_{t 0}-n_{t}\right)=n_{t 0}\left[1-\exp \left\{-Z\left(F-F_{t h}\right)\right\}\right]$

In the elastic region, $\mathrm{Z}\left(\mathrm{F}-\mathrm{F}_{\mathrm{th}}\right)$ is low, hence, Eq. (4) can be written as

$n_{d}=n_{t 0}\left[1-1+Z\left(F-F_{t h}\right)\right]=n_{t 0} Z\left(F-F_{t h}\right)$

Now, differentiating Eq. (5), we get

$\frac{d n_{d}}{d t}=n_{t 0} Z \frac{d F}{d t}$ 
As the rate of generation $g$ of electrons in the conduction band will be equal to the rate of detrapping of electrons, we can write

$$
g=n_{t 0} Z \frac{d F}{d t}
$$

If $\tau$ is the lifetime of electrons in the conduction band, then the change in the number of electrons in the conduction band can be expressed as

$\Delta n=g \tau=n_{t 0} Z \frac{d F}{d t} \tau$

Using Eq. (8), the current $\mathrm{j}$ flowing in the crystal can be written as

$j=\Delta n q v_{d}$

where $\mathrm{q}$ is the electronic charge and $\mathrm{v}_{\mathrm{d}}$ is the drift velocity.

If $\mu$ is the mobility of electrons in the crystals, then Eq. (9) can be expressed as

$j=\Delta n q \mu \mathrm{F}$

Thus, the rate $\mathrm{R}$ for the flow of electrons in the conduction band in the crystal is given by

$$
R=\frac{j}{q}=\Delta n v_{d}=\Delta n \mu F
$$

From Eqs. (8) and (11), we get

$$
R=\Delta n v_{d}=n_{t 0} Z \tau \mu F \frac{d F}{d t}
$$

If $\sigma$ is the capture-cross section of the energy state for the excited $\mathrm{Eu}^{2+}$ ions, and $\mathrm{n}_{\mathrm{h}}$ is the concentration of hole centres, then the rate of capture of electrons moving in the conduction band by the energy state of the excited $\mathrm{Eu}^{2+}$ ions or the rate of generation of excited $\mathrm{Eu}^{2+}$ ions can be expressed as, $\mathrm{R}$ $=\sigma n_{h} \Delta n v_{d}$, and the rate of generation of excited $\mathrm{Mn}^{2+}$ ions can be expressed as

$$
G=\sigma n_{h} \Delta n v_{d}=\sigma n_{h} n_{t 0} Z \tau \mu F \frac{d F}{d t}
$$

If $\eta$ is the efficiency for the radiative decay of excited $\mathrm{Mn}^{2+}$ ions, then the ML intensity for the total number $\mathrm{N}_{\mathrm{c}}$ of nanocrystallites in the sample, can be expressed as

$$
\begin{gathered}
I=\eta N_{c} G=\eta \sigma \mathrm{N}_{c} n_{h} n_{t 0} Z \tau \mu\left(F-F_{t h}\right) \frac{d F}{d t} \\
\text { or, } I=\eta \sigma \Omega \mathrm{N}_{\mathrm{c}} \mathrm{N}_{1} \mathrm{~N}_{\mathrm{t}} n_{h} Z \tau \mu\left(F-F_{t h}\right) \frac{d F}{d t}
\end{gathered}
$$

where $F_{t h}$ is the thresholds piezoelectric field for the ML emission.

If $\mathrm{B}$ is the correlating factor between the piezoelectric field $\mathrm{F}$ and the piezoelectric charge $\mathrm{Q}$, then, $\mathrm{F}=\mathrm{BQ}$, and $\mathrm{Eq}$. (14) can be written as

$$
I=\eta \sigma \Omega \mathrm{N}_{\mathrm{c}} \mathrm{N}_{1} \mathrm{~N}_{\mathrm{t}} n_{h} Z \tau \mu B^{2}\left(Q-Q_{t h}\right) \frac{d Q}{d t}
$$

where $\mathrm{F}_{\text {th }}=\mathrm{B} \mathrm{Q}_{\text {th }}$

Case I: EML induced by the stress initially increasing with time and then attaining a fixed value

\subsection{Rise of EML Intensity}

From Eqs. (1) and (15), we get

$I=\eta \sigma \Omega \mathrm{N}_{\mathrm{c}} \mathrm{N}_{1} \mathrm{~N}_{\mathrm{t}} n_{h} Z \tau \mu B^{2} d_{0}^{2}\left(P-P_{t h}\right) \frac{d P}{d t}$

In terms of strain rate, Eq. (16) can be expressed as

$I=\eta \sigma \Omega \mathrm{N}_{\mathrm{c}} \mathrm{N}_{1} \mathrm{~N}_{\mathrm{t}} n_{h} Z \tau \mu B^{2} d_{0}^{2} Y\left(P-P_{t h}\right) \dot{\varepsilon}$

Equation (17) indicates that for a given strain rate the ML intensity should increase linearly with the pressure, and for a given pressure, the ML intensity should increase linearly with the strain rate.

If $\mathrm{P}=\mathrm{P}_{\mathrm{m}}$, at $\mathrm{t}=\mathrm{t}_{\mathrm{m}}$, then for $\mathrm{P}_{\mathrm{m}} .>\mathrm{P}_{\mathrm{th}}$, from Eq.(16) the maximum EML intensity can be expressed as

$$
I_{m}=\eta \sigma \Omega \mathrm{N}_{\mathrm{c}} \mathrm{N}_{1} \mathrm{~N}_{\mathrm{t}} n_{h} Z \tau \mu B^{2} d_{0}^{2} \dot{P} P_{m}
$$

\subsection{Fast Decay of EML Intensity}

When the crosshead of the machine compressing the sample stops instantaneously, then the fast components of the EML decay does not appear and it appears only when the crosshead keeps on moving for some time after tuning off the electric power given to it. Thus, the fast decay of EML is related to the decrease of the strain rate of the sample with time. If $\tau_{\mathrm{m}}$ is the time-constant or machine constant for stopping the crosshead, then the decrease in strain rate with time can be expressed as

$$
\dot{\varepsilon}=\dot{\varepsilon}_{0} \exp \left[-\frac{\left(t-t_{m}\right)}{\tau_{m}}\right]=\dot{\varepsilon}_{0} \exp \left[-\phi\left(t-t_{m}\right)\right]
$$

where $\phi=1 / \tau_{m}, t_{m}$ is the time at which the electrical power to the crosshead is turned off, and $\dot{\varepsilon}_{0}$ is the strain rate at $\mathrm{t}=\mathrm{t}_{\mathrm{m}}$.

Using Eq. (19), $\dot{P}$ and $\mathrm{P}$ can be expressed as

$$
\dot{P}=Y \dot{\varepsilon}_{0} \exp \left[-\phi\left(t-t_{m}\right)\right.
$$

and, $P=P_{m}+\frac{Y \dot{\varepsilon}_{0}}{\phi}\left[1-\exp \left\{-\phi\left(t-t_{m}\right)\right\}\right]$

Using Eqs. (17), (19) and (21), the EML intensity for $\mathrm{P}$ $>>\mathrm{P}_{\text {th }}$, can be written as

$I=I_{m} \exp \left[-\phi\left(t-t_{m}\right)\right]$

\subsection{Slow Decay of EML Intensity}

During the deformation of the nanocrystals some of the detrapped electrons moving in the conduction band get trapped at the shallow traps lying in the normal piezoelectric region of the crystals where the piezoelectric field is less and later on such trapped electrons are thermally released form the traps and their subsequent capture in the excited states of $\mathrm{Eu}^{2+}$ ions gives rise to the light emission. In this case, the slow decay of EML intensity is given by 


$$
I_{d \mathrm{~s}}=I_{0 s} \exp \left[-\frac{\left(t-t_{c}\right)}{\tau_{s}}\right]=I_{0 s} \exp \left[-\chi\left(t-t_{c}\right)\right]
$$

where $t_{c}$ is the time at which the fast decrease of EML intensity becomes negligible, $\mathrm{I}_{0 \mathrm{~s}}$ is the EML intensity at $\mathrm{t}=\mathrm{t}_{\mathrm{c}}, \tau_{\mathrm{s}}=$ $1 / \chi$, is the lifetime of electrons in the shallow traps lying in the normal piezoelectric region of the crystals.

\section{(iv). Estimation of $I_{m}$ and $I_{T}$}

If the crystals is compressed at a fixed strain rate for a time $t_{m}$, where the pressure is $P_{m}$, then from Eqs. (16) and (17), the maximum intensity $\mathrm{I}_{\mathrm{m}}$ of the EML is given by

It is evident from Eq. (24) that the ML intensity will be maximum for the pressure $\mathrm{P}_{\mathrm{m}}$ corresponding to time $\mathrm{t}_{\mathrm{m}}$ at which the cross-head of the machine is stopped.

Integration of Eq. (16) gives that the total ML intensity $\mathrm{I}_{\mathrm{TD}}$ during the deformation of the sample can be expressed as intensity after $t_{m}$, the following two conditions arise: (i) occurrence of the detrapping in the localized piezoelectric region during the decay of piezoelectric charge, and (ii) occurrence of the EML decay from the filled shallow traps lying in the normal piezoelectric region of the crystals.

Condition I: Occurrence of the detrapping in the localized piezoelectric region during the decay of piezoelectric charge

In this case, after $t_{m}$, the pressure decreases with the rate $\dot{P}$, and therefore, the time dependence of pressure can be expressed as

$$
P=\dot{P}\left[t_{m}-\left(t-t_{m}\right)\right]=\dot{P}\left(2 t_{m}-t\right)
$$

where, $\dot{P}_{\mathrm{t}_{\mathrm{m}}}$ is the maximum pressure $\mathrm{P}_{\mathrm{m}}$ and $\dot{P}\left(\mathrm{t}_{\mathrm{t}}\right)$ is the decrease of pressure with time after $t_{m}$.

From Eq. (28), Q is given by

$I_{m}=\eta \sigma \Omega \mathrm{N}_{\mathrm{c}} \mathrm{N}_{1} \mathrm{~N}_{\mathrm{t}} n_{h} Z \tau \mu B^{2} d_{0}^{2}\left(P_{m}-P_{t h}\right) \frac{d P}{d t} \simeq \eta \sigma \Omega \mathrm{N}_{\mathrm{c}} \mathrm{N}_{1} \mathrm{~N}_{\mathrm{t}} n_{h} Z \tau \mu B^{2} d_{0}^{2} Y\left(P_{m}-P_{t h}\right) \dot{\varepsilon}$

$I_{T D}=\int_{0}^{t_{m}} I d t=\int_{0}^{I_{m}} \eta \sigma \Omega \mathrm{N}_{\mathrm{c}} \mathrm{N}_{1} \mathrm{~N}_{\mathrm{t}} n_{h} Z \tau \mu B^{2} d_{0}^{2}\left(P-P_{t h}\right) d P$

or, $\quad I_{T D}=\eta \sigma \Omega \mathrm{N}_{c} \mathrm{~N}_{1} \mathrm{~N}_{\mathrm{t}} n_{h} Z \tau \mu B^{2} d_{0}^{2} \frac{\left(P_{m}^{2}-2 P_{m} P_{t h}\right)}{2}$

or, $I_{T D} \simeq \eta \sigma \Omega \mathrm{N}_{\mathrm{c}} \mathrm{N}_{1} \mathrm{~N}_{\mathrm{t}} n_{h} Z \tau \mu B^{2} d_{0}^{2} \frac{P_{m}^{2}}{2}$

Equation (25) indicates that the total ML intensity in the deformation region should increase quardratically with the applied pressure.

Using Eq. (23), the value of total ML intensity from $t_{m}$ to $\propto$ is given by

$$
\begin{aligned}
& I_{T P D}=\int_{t_{m}}^{\infty} I_{m} \exp \left[-\chi\left(t-t_{m}\right)\right] d t \\
& \mathrm{r}, I_{T P D}=\frac{I_{m}}{\chi}
\end{aligned}
$$

From Eqs. (25) and (26), the total EML intensity is given by

$$
\begin{aligned}
& I_{T}=I_{D T}+I_{T P D}=\left(\frac{I_{m} P_{m}}{2}+\frac{I_{m}}{\chi}\right) \\
& \text { or, } I_{T}=\frac{\eta \sigma \Omega \mathrm{N}_{\mathrm{c}} \mathrm{N}_{1} \mathrm{~N}_{\mathrm{t}} n_{h} Z \tau \mu B^{2} d_{0}^{2} P_{m}^{2}}{2}\left(1+\frac{2 \tau_{s}}{t_{m}}\right)
\end{aligned}
$$

Case II.EML induced by the stress initially increasing and then decreasing with time

For the increasing portion of pressure, $\mathrm{I}_{\mathrm{m}}$ and $\mathrm{I}_{\mathrm{T}}$ are given by Eqs. (18) and (27), respectively.For the decay of EML
$Q=d_{0} P=d_{0} \dot{P}\left(2 t_{m}-t\right)$

Now, from Eq. (29), dQ/dt, is given by

$\frac{d Q}{d t}=-d_{0} \dot{P}$

Equation (16) indicates that for $\mathrm{Q}>>\mathrm{Q}_{\mathrm{th}}$, the EML intensity $\mathrm{I}$ is proportional to the product of $\mathrm{Q}$ and $\mathrm{dQ} / \mathrm{dt}$. Thus, Eqs. (29) and (30) give

$I=D d_{0}^{2} \dot{P}^{2}\left(2 t_{m}-t\right)$

where $\mathrm{D}$ is the proportionality constant

As $\mathrm{I}=\mathrm{I}_{\mathrm{m}}$, at $\mathrm{t}=\mathrm{t}_{\mathrm{m}}$, we get $D d_{0}^{2} \dot{P}^{2}=I_{m} / t_{m}$, and therefore, the decay of EML intensity can be expressed as

$I_{d s}=\frac{I_{m}}{t_{m}}\left(2 t_{m}-t\right)$

Condition II: Occurrence of the EML decay from the filled shallow traps lying in the normal piezoelectric region of the crystals

In the second condition, the decay of EML intensity can also be expressed using Eq. (23), where the EML intensity will decrease exponentially with time and the decay time of EML will be equal to the lifetime of electrons in the shallow traps lying in the normal piezoelectric region of the crystals, at which the piezoelectric field is less.

Case III: EML induced by impact stress In the impulsive deformation, a small steel ball is dropped on to the film of nanoparticles from a low height, so that the impact stress remains in the elastic region. If the ball of mass $m$ is dropped from height $h$, then its kinetic energy is $1 / 2 \mathrm{mv}^{2}=\mathrm{mgh}$, where 
$v$ is the velocity of ball and $g$ is the acceleration due to gravity. If a fraction $f$ of the elastic energy of impacting ball is given to the film and substrate whose total volume is $\mathrm{V}$, then the elastic energy will be $\sigma^{2} \mathrm{~V} / 2 \mathrm{Y}$, where $\mathrm{Y}$ is the Young's modulus elasticity. Thus, we can write

$f m g h=\frac{\sigma_{0}^{2} V}{2 Y}$

or, $\sigma_{0}=\left(\frac{2 f m g h Y}{V}\right)^{\frac{1}{2}}$

where $\sigma_{0}$ is the maximum value of the impact stress.

During the impact of a ball the energy is transferred to the sample, substrate and base on which the sample is placed, and some of the energy is also transferred into the rebounding energy of the ball. Thus, only a fraction of the kinetic energy of the ball is given to the sample. For $\mathrm{m}=$ $5.75 \mathrm{gm}[19,50], \mathrm{h}=17 \mathrm{~cm}[19,50], \mathrm{g}=981 \mathrm{~cm} / \mathrm{s}^{2}$, and $\mathrm{Y}=$ $6.72 \times 10^{11}$ dyne $/ \mathrm{cm}^{2}$ [64], $\sigma_{0}$ comes out to be nearly 8,16 and $22 \mathrm{MPa}$ for $\mathrm{f}=0.05,0.25$ and 0.50 , respectively. As the Young's modulus of elasticity is less for nanoparticles as compared to that of the bulk $[65,66]$, the theoretically estimated value of $\sigma_{0}$ should be less for the nanoparticles.

From the comparison of the piezoelectric charge induced by impact with that of the statical load, the impact stress to for $\mathrm{m}=5.75 \mathrm{gm}$ and $\mathrm{h}=17 \mathrm{~cm}$, comes out to be nearly 9 MPa [39], and practically this value should be more correct. From the stress-strain curve of $\mathrm{ZnS}$ crystals, the stress corresponding to the limit of elasticity comes out to be nearly 30 $\mathrm{MPa}$ [39].Thus, the maximum value of the impact stress is in the elastic region, and no fracture of the $\mathrm{ZnS}: \mathrm{Mn}$ film should occur due to the impact of a small ball from a low height, and consequently, the fracto ML may not appear.

After the impact, initially the stress increases with time, attains a peak value and later on it decreases with time. If $\tau_{\mathrm{r}}$ $=1 / \xi$, is the time-constant for rise of stress, then the rise of stress can be expressed as [24]

$\sigma=\sigma_{0}[1-\exp (-\xi t)]$

In this case, $-\mathrm{dQ} / \mathrm{dt}=\mathrm{d}_{0} \mathrm{d \sigma} / \mathrm{dt}$, and $\mathrm{Q}=\mathrm{d}_{0} \sigma$, and following the procedure described in section 5 , case $\mathrm{I}, \mathrm{I}_{\mathrm{m}}, \mathrm{I}_{\mathrm{TD}}, \mathrm{I}_{\mathrm{df}}$, and $\mathrm{I}_{\mathrm{ds}}$ can be expressed as

$I_{m}=\frac{\eta \Omega \mathrm{N}_{\mathrm{c}} \mathrm{N}_{1} \mathrm{~N}_{\mathrm{t}} n_{h} Z \tau \mu B^{2} d_{0}^{2} Y f m g h}{V}$

$I_{T D}=\frac{\eta \sigma \Omega \mathrm{N}_{c} \mathrm{~N}_{1} \mathrm{~N}_{\mathrm{t}} n_{h} Z \tau \mu B^{2} d_{0}^{2} \text { Yfmgh }}{V}$

$I_{d f}=I_{m} \exp \left[-\xi\left(t-t_{m}\right)\right]$

and, $I_{d s}=I_{d s}^{0} \exp \left[-\chi\left(t-t_{c}^{\prime}\right)\right]$

where $\chi=\left(1 / \tau_{s}\right)$, is the lifetime of electrons in the shallow traps, $t_{c}$ is the time at which the piezoelectric charge becomes negligible and $I_{d s}^{0}$ is the EML intensity at $\mathrm{t}=t_{c}^{\prime}$.
The expressions derived for the dependence of EML intensity on different parameters are able to explain satisfactory the characteristics of the EML of nanoparticles. The values of $\xi$ and $\chi$ are determined using Eqs.(37) and (38), ,respectively and they are found to be $0.045 \mathrm{~ms}^{-1}$ and 0.013 $\mathrm{ms}^{-1}$ for $\mathrm{ZnS}: \mathrm{Mn}$ nanocrystals. and $\mathrm{SrAl}_{2} \mathrm{O}_{4}: \mathrm{Eu}$, respectively.Thus, the value of $\tau_{\mathrm{r}}=1 / \xi$, comes out to be $22.22 \mathrm{~ms}$, and the value of $\tau_{\mathrm{s}}=1 / \chi$, comes out to be $22.22 \mathrm{~ms}$.

\section{IMPORTANCE OF THE EML OF NANOPARTI- CLES}

The elastico ML of $\mathrm{ZnS}: \mathrm{Mn}$ and $\mathrm{SrAl}_{2} \mathrm{O}_{4}$ : Eu, Dy microcrystals or nanoparticles can be used for the following purposes:

\subsection{Stress Sensor}

As the ML intensity of $\mathrm{ZnS}: \mathrm{Mn}$ and $\mathrm{SrAl}_{2} \mathrm{O}_{4}$ : Eu, Dy phosphors mixed in a resin increases with increasing stress or the applied pressure, the stress or the pressure can be determined by measuring the EML intensity. As such the EML of $\mathrm{ZnS}: \mathrm{Mn}$ and $\mathrm{SrAl}_{2} \mathrm{O}_{4}$ : Eu, Dy can be used as stress sensor or stress indicator.

\subsection{Real -Time Visualization of the Stress Distribution in Solids}

For the measurement of stress distribution using the ML technique, $\mathrm{SrAl}_{2} \mathrm{O}_{4}$ : Eu phosphor of $1.00 \mathrm{~g}$ is mixed with an optical epoxy resin of $4.00 \mathrm{~g}$ to form a composite disc of 25 $\mathrm{mm}$ in diameter and $15 \mathrm{~mm}$ in thickness. Stress is applied on the sample by a normal material testing machine or by a vise with a force gauge $[6,7,9]$. The distribution of ML intensity is detected by an intensified CCD (ICCD) camera. The ML intensity of such a stressed sample increases exponentially with increasing $\mathrm{r} / \mathrm{a}$ (where $\mathrm{r}$ is the distance from the centre, and $a$ is the radius of sample). This is consistent with that obtained from the simulation based on elastics, and thus, it demonstrates that the EML from stressed $\mathrm{SrAl}_{2} \mathrm{O}_{4}$ : Eu gives the direct view of stress distribution in solids.

\subsection{Real-Time Visualization of the Stress Field Near the Tip of a Crack}

For the direct observation of crack tip stress field using ML, Sohn et al., [14] prepared the compact test (CT) specimen $(19 \mathrm{~mm} \times 20 \mathrm{~mm} \times 3 \mathrm{~mm})$ from a mixture of epoxy resin and $10 \mathrm{wt}$. \% of $\mathrm{SrAl}_{2} \mathrm{O}_{4}: \mathrm{Eu}, \mathrm{Dy}, \mathrm{Nd}$, phosphor. $\mathrm{An}$ acute notch tip of radius $50 \mu \mathrm{m}$ was introduced into the CT specimen using a very sharp blade for providing a crack initiation point. The specimen was placed on a specially designed CT type loading machine and exposed to $365 \mathrm{UV}$ light for 10 minutes and then aged in a dark room for $5 \mathrm{~min}-$ utes for the phosphorescence to relax down to a certain level before loading. The notch tip area was photographed at each loading step using a digital camera with shutter open. It became possible to investigate the stress field formation in front of a stationary crack- tip in terms of ML for a stress intensity factor of $1.7 \mathrm{M} \mathrm{Pa} \mathrm{m}{ }^{1 / 2}$, whereby the formation of circle-shaped stressed area was evident. Such result is expected from fracture mechanics. 


\subsection{Real-Time Visualization of the Quasidynamic Crack-Propagation in Solids}

For studying the dynamic visualization of crack propagation and bridging stress using the $\mathrm{ML}$ of $\mathrm{SrAl}_{2} \mathrm{O}_{4}$ : Eu,Dy,Nd, Kim et al. [27] prepared a disc-shaped CT specimen of dimension $26 \mathrm{~mm}$ in diameter and $3 \mathrm{~mm}$ thickness from a bulk $\mathrm{SrAl}_{2} \mathrm{O}_{4}: \mathrm{Eu}_{0.01}, \mathrm{Dy}_{0.01}, \mathrm{Nd}_{0.01}$ ceramic, without mixing epoxy resin. The $\mathrm{R}$-curve was determined where the crosshead speed was $1 \mathrm{~mm} / \mathrm{min}$ and the photography frame speed was 30 frames /sec. The loading process associated with the ML observation was followed by microscopic observation of crack wake region using scanning electron microscopy. The ML images were taken for the crack propagation time of 0.3 sec, whereby the crack propagated nearly $6.5 \mathrm{~mm}$. In this case, the conspicuous ML emission takes place from the area adjacent to the crack plane rather than from the area ahead of the crack tip. The more prominent ML in the crack wake region provides a good circumstantial evidence for crack interface bridging and a diminished stress intensity factor at the crack tip. The length of the strong ML region or strong bridging effect region, just behind the crack tip grows as the crack propagates and the ML intensity also becomes stronger as the crack advances. The $\mathrm{R}$-curve was determined using ML measurements and it was compared with the best fit based on power law bridging stress distribution. The bridging stress distribution in the crack wake was determined from the results of regression fitting used in $\mathrm{R}$-curve. Recently, Kim et al. [28, 29] have also studied the propagation of a macro scale crack in other ceramic materials using $\mathrm{SrAl}_{2} \mathrm{O}_{4}$ : Eu, Dy mechanoluminescent paint.

\subsection{Visualization of Internal Defect in a Pipe}

A defect in a pressurized pipe can be visualized by using ML sensor [67]. The hoop strain distribution obtained from the ML intensity agrees well with that obtained from the strain gage measurement and the FEM calculation. It has been found that the hoop strain on the defective pipe has maximum and minimum values around the defect and the maximum hoop strain increases with deepening of the defect. Thus, these results indicate that the location and depth of the defect in a pipe can be estimated by using the ML sensor.

\subsection{Determination of the Crack-Growth Resistance and other Parameters of Crack- Propagation}

Using the ML technique, crack growth resistance curve (R-curve), crack velocity, crack-length dependence of crackvelocity, crack-tip stress field, bridging stress distribution, wake width, etc. can be suitably determined. The ML technique is much simpler, cheaper and more suited to the detection of fast cracks as compared to other techniques involving complicated and expensive instrumentations [27-29].

\subsection{Novel ML-Driven Photocell System}

Terasaki et al., [68] have successfully demonstrated a novel ML-driven photocell system, in which $\mathrm{SrAl}_{2} \mathrm{O}_{4}: \mathrm{Eu}$, microparticles and a commercial silicon solar cell are used as light source and a photoelectric converter, respectively.

\subsection{Light Source}

From the viewpoint of utilizing a mechanoluminescent material as a light source, the surface of the ML material should have the most effective photoreaction and there should be the strongest photointensity from the ML material. Terasaki [69] have reported the preparation method for a hybrid material consisting of the ML material $\left(\mathrm{SrAl}_{2} \mathrm{O}_{4}: \mathrm{Eu}\right)$ and $\mathrm{TiO}_{2}$ photocatalytic nanoparticles. By using the surface sol-gel method, they have succeeded in immobilizing the $\mathrm{TiO}_{2}$ photocatalytic nanoparticles on the surface of the ML material, thus preparing a hybrid material where the nanoparticles took over the original mechanoluminescence and photocatalysis activities.

\subsection{EML-Based Safety-Management Monitoring System}

An EML-based safety-management monitoring system has been developed [70] that includes: (i) EML sensors that emit light upon mechanical stimulation, (ii) image sensors nodes that monitor the distribution of EML intensity of the EML sensors, (iii) wireless photo-detector nodes, (iv) a database for diagnosing the stress anomaly in the structure on the basis of the EML intensity, and (v) a network system that coordinates the operation of these component. Using this system the appearance of a crack that occurs in the concrete of bridges and buildings can be visualized, when the EML sensors of the system are placed on the structure surfaces. The generation and propagation of the crack can be predicted by diagnosing the stress anomaly in the structure. Such EML-based monitoring system is expected to be useful for the inspection and maintenance of various structures including those made of concrete.

\section{CONCLUSIONS}

The temporal, deformation, spectral and other characteristics of the elastico ML of thin film of $\mathrm{ZnS}$ nanoparticles and $\mathrm{SrAl}_{2} \mathrm{O}_{4}$ :Eu nanoparticles mixed in epoxy resin are studied by elastically deforming the samples using statical, impulsive and friction techniques. The piezoelectricallystimulated detrapping model is found to be suitable for the EML of nanoparticles. The expressions derived on the basis of this model, are able to explain satisfactorily the characteristics of the EML of nanoparticles.

For the fixed pressure or slowly decreasing pressure, the slow decay time of EML is equal to the lifetime of electrons in the shallow traps lying in the normal piezoelectric region of the crystals.In these cases, sometimes, fast decay of EML also appears and it is related to the machine -constant, that is, the decay time of strain- rate after the power to the crosshead of the machine is switched off. For the fast-deformation caused by impact stress, the fast decay time of EML is controlled by the rise time of impact stress, and the slow decay of EML gives the lifetime of retrapped electrons in the shallow traps. For $\mathrm{ZnS}: \mathrm{Mn}$ and $\mathrm{SrAl}_{2} \mathrm{O}_{4}: \mathrm{Eu}$ nanoparticles, the total EML intensity increases quadratically with the applied pressure. The diminished EML intensity of $\mathrm{SrAl}_{2} \mathrm{O}_{4}: \mathrm{Eu}$ nanoparticles caused by number of pressings can be recovered by exposing the sample to UV-radiation. The EML spectra of $\mathrm{ZnS}: \mathrm{Mn}$ and $\mathrm{SrAl}_{2} \mathrm{O}_{4}: \mathrm{Eu}$, nanoparticles are similar to their photoluminescence and electroluminescence spectra. 
The tribo ML of ZnS:Mn nanoparticles increases with increasing value of the load placed on the rotating rod inducing tribo ML. The tribo ML may be induced by the triboelectrification and /or piezoelectrification

The EML of nanoparticles can be useful in stress sensor and for the visualizations of stress distribution in solids, stress field near crack-tip, quasidynamic crack-propagation in solids and internal defect in a pipe. An EML-based safetymanagement monitoring system has been developed for visualizing the appearance of a crack that occurs in the concrete of bridges and buildings. The generation and propagation of the crack can be predicted by diagnosing the stress anomaly in the structure. Such EML-based monitoring system is expected to be useful for the inspection and maintenance of various structures including those made of concrete. The EML intensity of nanoparticles is so intense that it is able to drive a solar cell system and it can also be used as an excitation source for specific applications. Furthermore, several parameters of nanoparticles can be determined from their EML measurements.

In addition to the mechanical displays, the coating of mechanoluminescent materials has opened a new window for developing new smart systems and opto-mechanical devices. Conclusively, it may be said that the door of EML research on nanoparticles is wide open and it looks very promising.

\section{ACKNOWLEDGEMENT}

The author is thankful to Shri S.K. Jain, Chairman Disha Education Society, Raipur (C.G.), India for his support.

\section{CONFLICT OF INTEREST}

None.

\section{REFERENCES}

[1] Chandra, B. P. In Luminescence of Solids, D. R. Vij,ed.; Plenum Press: New York, 1998, pp 361-389.

[2] Meyer, K; Obrikat, D; Rossberg, M.. Progress in triboluminescence of alkali halides and impurity doped zinc sulpdides. Kristall. $U$. Tech., 1970; 5, 5; ibid 5, 181.

[3] Walton, A.J. Triboluminescence . Adv. Phy., 1977, 26, 887.

[4] Molotskii, M.I.. Electronic excitation during the plastic deformation and fracture of crystals. Sov. Sci. Rev. B. Chem., 1989, 13, 1.

[5] Chandra, B.P.; Mahobia, S.K.; Jha, P.; Kuraria, R.K.; Kuraria, S.R.; Baghel, R.N.; Thaker, S. Transient behavior of the mechanoluminescence induced by impulsive deformation of fluorescent and phosphorescent crystals. J. Lum., 2008, 128, 2038.

[6] Xu, C.N. In Encyclopedia of Smart Materials, M. Schwart, ed.; John Willey \& Sons, Inc.: New York, 2002; vol. 1, pp 190-201.

[7] Akiyama, M.; Xu, C.N.; Taira, M.; Nonaka, K. Visualization of stress distribution using mechanoluminescence from $\mathrm{Sr}_{3} \mathrm{Al}_{2} \mathrm{O}_{6}: \mathrm{Eu}$ and the nature of the luminescence mechanism. Philos. Mag. Lett., 1999, 79, 735 .

[8] Akiyama, M.; Xu, C.N; Liu, Y.; Nonaka, K.; Watanbe, T. Influence of Eu, Dy co-doped strontium aluminate composition on mechanoluminescence intensity. J. Lum., 2002, 97, 13.

[9] Xu, C.N.; Watanabe, T.; and Akiyama, M. Direct view of stress distribution in solids by mechanoluminescence. Appl. Phys., Lett., 1999, 74, 2414.

[10] Xu, C.N.; Yamada, H.; Wang, X.; Zheng, X.G. Strong elasticoluminescence from monoclinic structure $\mathrm{SrAl}_{2} \mathrm{O}_{4}$. Appl. Phys. Lett., 2004, 84, 3040.

[11] Sakaihara, I.; Tanaka, K.; Wakasugi, T.; Ota, R. Triboluminescence of $(\mathrm{Sr}, \mathrm{Ba}) \mathrm{Al}_{2} \mathrm{O}_{4}$ Polycrystals Doped with $\mathrm{Eu}^{3+}$ and $\mathrm{Eu}^{2+}$, Jpn. J. Appl. Phys., 2002, 41, 1419.
[12] Lin, Y.H.; Dang, Z.; Deng, Y.; Nan, C.W. Studies on mechanoluminescence from $\mathrm{SrAl}_{2} \mathrm{O}_{4}$ : $\mathrm{Eu}$, Dy phosphors. Mat. Chem. and Phys., 2003, 80, 20.

[13] Jia, Y.; Yei , M.; Jia , W. Stress-induced mechanoluminescence in $\mathrm{SrAl}_{2} \mathrm{O}_{4}: \mathrm{Eu}^{2+}, \mathrm{Dy}^{3+}$. Opt. Mat., 2006, $28,974$.

[14] Sohn, K.S.; Seo, S.Y.; Kwon, Y.N.; Park, H.D. Direct observation of crack tip field using the mechanoluminescence of $\mathrm{SrAl}_{2} \mathrm{O}_{4}: \mathrm{Eu}$, Dy, Nd. J. Am. Cream Soc., 2002, 85, 712.

[15] Kim, J.S.; Koh, H.J.; Lee, W.D.; Shin, N.; Kim, J.G.; Lee, K.H.; Sohn, K.S. Quasidynamic visualization of crack propagation and wake evolutionin Y-TZP ceramic by mechanoluminescence. Met. and Matrs. Int., 2008, 14, 165.

[16] Chandra, B.P.; Baghel, R.N.; Luka, A.K.. Sanodiya, T.R; Kuraria, R.K.; Kuriaria, S.R. Strong mechanoluminescence induced by elastic deformation of rare earth doped strontium aluminate phosphors. J. Lum., 2009, 129, 760.

[17] Kim, J.S.; Kibble, K.; Kwon, Y.N.; Sohn, K.S. Rate-equation model for the loading-rate-dependent mechanoluminescence of $\mathrm{SrAl}_{2} \mathrm{O}_{4}: \mathrm{Eu}^{2+}, \mathrm{Dy}^{3+}$. Opt Lett., 2009, 34,1995.

[18] Li, C.; Xu, C.N.; Zhang, L.; Yamada, Imai, H.Y. Dynamic Visualization of Stress Distribution by Mechanoluminescence Image. Key Eng. Matrs., 2009, 38, 8265.

[19] Xu, C. N.; Watanabe, T.; Akiyama, M.; Zheng, X. G. Artificial skin to sense mechanical stress by visible light emission. Appl. Phys. Lett., 1999, 74, 1236.

[20] Xu, C.N.; Watanabe, T.; Akiyama, M.; Zheng, X.G. Preparation and characteristics of highly triboluminescent thin film. Matrs. Res. Bull., 1999, 34, 1491.

[21] Xu, C. N.; Watanabe, T.; Akiyama, M. Development of strongly adherent triboluminescent zinc sulphide films on glass substrates by ion plating and annealing. J. Am. Ceramic Soc., 1999, 82, 2342.

[22] Xu, C. N.; Zheng, X. G.; Watanabe, T.; Akiyama, M.; Usui, I. Enhancement of adhension and triboluminescence of $\mathrm{ZnS}$ : M films by annealing technique. Thin Solid Films, 1999, 352, 273.

[23] Agyeman, B. O.; Xu, C. N.; Shi, W.; Suzuki, M.; Zheng, X. G. Triboluminescence of $\mathrm{ZnS}$ : Mn films deposited on quartz substrates with $\mathrm{ZnO}$ buffer layers. Jpn. J. Appl. Phys., 2002, 41, 5259.

[24] Chandra, B.P.; Xu, C.N.; Yamada, H.; Zheng, X.G. Luminescence induced by elastic deformation of $\mathrm{ZnS}: \mathrm{Mn}$ nanoparticles. J. $\mathrm{Lu}$ min., 2010, 130, 442.

[25] Li, C.; Xu, C. N.; Yamada, H.; Imai, Y.; Zhang, H; Zhang, L.A. Novel technique for viewing stress distribution with mechanoluminescence materials. Key Eng. Matrs., 2008, 1407, 368-372.

[26] Sohn, K. S.; Seo, S. Y.; Kwon, Y. N.; Park, H. D. Direct observation of crack tip field using the mechanoluminescence of $\mathrm{SrAl}_{2} \mathrm{O}_{4}$ : Eu, Dy, Nd, J. Am. Cer. Soc., 2002, 85, 712.

[27] Kim, J.S.; Kwon, Y. N.; Sohn, K. S. Dynamic visualization of crack propagation and bridging stress distribution using the mechanoluminescence of SrAl2O4: (Eu,Dy,Nd). Act. Matr., 2003, 51, 6437.

[28] Kim, J.S.; Kwon, Y.N.; Shin, N.; Sohn, K.S. Visualization of fractures in alumina ceramics by mechanoluminescence. Act. Matr., 2005, 53, 4337.

[29] Kim, J. S.; Kwon, Y. N.; Shin; Sohn, K. S. Mechanoluminescent $\mathrm{SrAl}_{2} \mathrm{O}_{4}$ : Eu,Dy phosphor for use in visualization of quasidynamic crack propagation. Appl. Phys. Lett., 2007, 90, 241916.

[30] Xu, C. N.; Li, C.; Imai, Y.; Yamada, H.; Adachi, Y.; Nishikubo, K Development of elastico-luminescent nanoparticles and their applications. Adv. in Sci. and Tech., 2006, 45, 939.

[31] Li.; C.; Adachi, Y.; Imai, Y.; Nishikubo, K.; Xu, C.N. Processing and Properties of $\mathrm{SrAl}_{2} \mathrm{O}_{4}$ : Eu Nanoparticles Prepared via PolymerCoated Precursor. J. Electrochem. Soc., 2007, 154, J362.

[32] Raja, R. D.; Reddy, B.K. Laser-like mechanoluminescence in ZnMn Te diluted magnetic semiconductor. Appl. Phys. Lett., 2002, 81,460 .

[33] Lu, H.Y.; Chu, S.Y. The mechanism and characteristics of $\mathrm{ZnS}$ based phosphor powders. J. Crys. Gr., 2004, 265, 476.

[34] Chudacek, I. The influence of pressure on recombination centres in piezoelectric luminophors, Czech. J. Phys., 1966, B16, 520.

[35] Chudacek, I. The kinetics of the triboluminescence of zinc sulphide I, Czech. J. Phys., 1967, B17, 34

[36] Chudáček, I.; Sodomka, L. The influence of pressure on the luminiscence of zinc sulfide single crystals. Czech. J. phys., 1963, B13, 209. 
[37] Sodomka, L. The form of pressure and luminescence brightness during impact on a luminescent layer, Czech. J. Phys., 1964, B14, 800 .

[38] Meyer, K; Obrikat, D; Rossberg, D. The triboluminescence of zinc sulphides and alkali halides. Phys. Stat. Sol., 2006, 35, K13.

[39] Osipyan, Yu. A.; Petrenko, V. F.; Zaretskii, A. V.; Whitworth, R. W. Properties of II-VI semiconductors assosiated with moving dislocations. Adv. Phys., 1986, 35, 115.

[40] Bredikhin, S.I.; Shmurak, S.Z. Interaction between charged dislocations and luminescence centres in $\mathrm{ZnS}$ crystals. Sov. Phys. JETP., 1979, 49, 520 .

[41] Valiev, Z.A. Theory of deformation luminescence of crystals with moving charged dislocations. Sov. Phys. Sold. St., 1986, 28, 1632.

[42] Vardayan, R.A.; Veselkov, S.G.; Kirikosyah, G.G. Luminescence of deep centres in plastically deformed semiconductors. Sov. Phys. Sold. St., 1989, 31, 12.

[43] Chandra, B.P. Luminescence induced by moving dislocations in crystals. Rad. Eff. and Def. in Sol., 1996, 138, 883 .

[44] Penn, R.L.; Banfield, J.F. Imperfect oriented attachment: dislocation generation in defect-free nanocrystals. Sci., 1998, 281, 969.

[45] Carlton, C.E.; Rabenberg, I.; Ferreira, P.J. On the nucleation of partial dislocations in nanoparticles. Phil. Mag. Lett., 2008, 88, 715 .

[46] Timoshenko, Yu. K.; Shunina, V.A. Electronic structure of the $\mathrm{KCl}$ and $\mathrm{AgCl}$ nanocrystals with edge dislocations. Phys. St. Sol. (c), 2005, 2, 1791.

[47] Banfield, J.F.; Zhang, H. Nanoparticles in environment. Rev. in Min. and Geochem., 2001, 44, 1.

[48] Gilbert, F.; Huang, Z. H.; Waychunasga; Banfield, J.F. Nanoparticles: Strained and Stiff. Science, 2004, 305, 651.

[49] Zhang, H.; Gilbert, B.; Huang, F.; Banfield, J.F. Water-driven structure transformation in nanoparticles at room temperature. $\mathrm{Na}$ ture, 2003, 424, 1025.

[50] Xu, C.N.; Akiyama, M.; Nonaka, K.; Watanabe. Electrical power generation characteristics of PZT piezoelectric ceramics, T. IEEE Transact. on Ultrason., Ferroelect., and Freq. Con., 1998, 45, 1065 .

[51] Chandra, B.P.; J. Lum. Mechanoluminescence induced by elastic deformation of coloured alkali halide crystals. 2008, 128, 1217.

[52] Alzetta, G.; Minnaja, N.; Santucci, S. Piezoluminescence in zinc sulphide phosphors. Nuo. Cimt., 1962, 33, 911.

[53] Scarmozzino, R. Piezoluminescence in zinc sulphide phosphors. Sol. St. Comm., 1971, 9, 1759.

[54] Kobyakov, I.B. Piezoelectric, elastic and dielectric constants of hexagonal zinc sulphide. Sov. Phys.- Cryst., 1966, 11, 369.

[55] Sage, I.; Bourhill, G. J. Mater, Triboluminescence materials for structural damage monitoring. Chemistry, 2001, 11, 221.
[56] Chandra, B.P.; Rathore, A.S. Classification of mechanoluminescence. Cryst. Res. Tech., 1995, 30, 885.

[57] Grmela, L.; Macku, R.; Tomanek, P. Near-field measurement of ZnS: Mn nanocrystals and bulk thin-film electroluminescent devices. J. Mic., 2008, 229, 275.

[58] Wood, V.; Halpart, J. E.; Panzer, M.J.; Bawend, M.G.; Bulonic, V. Alternating current driven electroluminescence from ZnSe/ZnS:Mn/ZnS nanocrystals. Nan. Lett., 2009, 9, 2367.

[59] Manzoor, K.; Vadera, S.R.; Kumar, N.; Kutty, T.R.N. Multicolor electroluminescent devices using doped ZnS nanocrystals. Appl. Phys. Lett., 2004, 84, 284.

[60] Suyver, J.F.; Wuister, S.F.; Kelly and Meijrink, A. Synthesis and Photoluminescence of Nanocrystalline $\mathrm{ZnS}: \mathrm{Mn}^{2+}$. Nan. Lett., 2001, 1,429 .

[61] Clabau, F.; Rocquelte, X.; Jobic, S.; Deniard, P.; Whangbo, M.; Garcia, A.; Mercier, T. Le. Mechanism of phosphorescence appropriate for the long-lasting phosphors $\mathrm{Eu}^{2+}$-doped $\mathrm{SrAl}_{2} \mathrm{O}_{4}$ with codopants $\mathrm{Dy}^{3+}$ and $\mathrm{B}^{3+}$. Chem. Mater., 2005, 17, 3904.

[62] Clabau, F; Rocquelte, T. Le X.; Mercier, T. Le; Deniard, P.; Jobic, S.; Whangbo, M. Formulation of phosphorescence mechanisms in inorganic solids based on a new model of defect conglomeration. Chem. Mater., 2006, 18, 3212.

[63] Clabau, F.; Garcia, A.; Bonville, P.; Gonbeau, D.; Mercier, T.L.; Deniard, P.; Jobic, S. Fluorescence and phosphorescence properties of the low temperature forms of the $\mathrm{MAl}_{2} \mathrm{Si}_{2} \mathrm{O}_{8}: \mathrm{Eu}^{2+}(\mathrm{M}=\mathrm{Ca}, \mathrm{Sr}, \mathrm{Ba})$ compounds. Solid State Chem., 2008, 181, 1456.

[64] Berger, L.I. Semiconductor Materials; CRC Press: Boca Ratan, Fluorida, 1997.

[65] Thomas, B.; Abdulkhadar, M. Elastic properties ofconsolidated nanoparticles of ZnS and CdSSol. St. Comm., 1995, 94, 205.

[66] Ouyang, G.; Li, X.L.; Tan, X. and Yang, G.W. Size-induced strain and stiffness of nanocrystals. Appl. Phys. Lett., 2006, 89, 031904.

[67] Ono, D.; Xu, C.N.; Li, C.; Bu, N. Visualization of Internal Defect of a Pipe Using Mechanoluminescent Sensor. J. Jpn. Soc. Exp. Mech. (JSEM), 2010, 10, 152.

[68] Terasaki, N.; Xu, C.N.; Imai, Y.; Yamada, H. Photocell System Driven by Mechanoluminescence. Jpn. J. Appl. Phy., 2007, 46, 2385.

[69] Terasaki, N.; Zhang, H.; Imai, Y.; Yamada, H.; Xu, C.N. Hybrid material consisting of mechanoluminescent material and $\mathrm{TiO} 2$ photocatalyst. Thin Solid Films, 2009, 518, 473.

[70] Xu, C.N. Monitoring system for safety management of structures using elastico-luminescent materials- Real-time visualization of the shape distribution and propagation of cracks using elasticoluminescent sensors. AIST Today, 2010, 10, 18.

Received: August 07, 2011

Revised: September 07, 2011

Accepted: October 04, 2011

(C) B.P. Chandra et al.; Licensee Bentham Open.

This is an open access article licensed under the terms of the Creative Commons Attribution Non-Commercial License (http://creativecommons.org/licenses/by-nc/3.0/) which permits unrestricted, non-commercial use, distribution and reproduction in any medium, provided the work is properly cited. 